\title{
A Comparison of Widespread Flexible Residential Electric Heating and Energy Efficiency in a Future Nordic Power System
}

\author{
Topi Rasku * (D) and Juha Kiviluoma \\ VTT Technical Research Centre of Finland Ltd., FI-02044 VTT Espoo, Finland; juha.kiviluoma@vtt.fi \\ * Correspondence: topi.rasku@vtt.fi
}

Received: 12 November 2018; Accepted: 14 December 2018; Published: 20 December 2018

\begin{abstract}
Integrating ever-increasing amounts of variable renewable energy (VRE) into the power system could benefit from harnessing widespread residential demand-side management. This paper presents case studies on the potential benefits of power-to-heat $(\mathrm{P} 2 \mathrm{H})$ flexibility and energy efficiency improvements in a hypothetical future Finnish detached housing stock in the year 2030, both as a part of the larger Nordic power system and in an isolated Finnish power system. The housing stock was depicted using two archetype houses modeled using a simple lumped capacitance approach, integrally optimized as a part of a stochastic linear programming unit commitment model of the power system. With sufficient amounts of VRE, residential P2H with thermal storage was found to yield more system cost savings than simple energy efficiency improvements. However, energy efficiency improvements remained more beneficial for house owners, as excessive use of residential P2H for assisting the power system could result in increased heating costs.
\end{abstract}

Keywords: demand-side management; demand response; energy efficiency; power-to-heat; electric heating systems; renewable energy integration

\section{Introduction}

With the world producing ever-increasing amounts of renewable energy [1] at record-low costs [2], energy systems are likely to rely increasingly on power generation from variable renewable energy (VRE) sources. This will challenge the traditional role of the generation side in matching electricity demand, as generation from VRE is bound to the vagaries of weather. In addition to more conventional solutions, e.g., investing in peak-load power plants or transmission capacity, various energy storage and demand-side management (DSM) solutions are being researched as potential alternatives [3].

DSM is by no means a new technology, and different demand response schemes have been utilized for decades, particularly in the energy-intensive parts of the industrial sector [4]. With improvements in communications technology and adaptation of smart metering, various DSM solutions are becoming increasingly more viable within the residential sector as well. Devices such as electric heating systems and electric vehicles have received their fair share of academic attention [3,5,6], as they represent ideal candidates for DSM within the residential sector. Additionally, the ongoing electrification trend in the heating and transportation sectors aiming towards a decarbonized society $[7,8]$ will likely increase interest in power-to-heat $(\mathrm{P} 2 \mathrm{H})$ and vehicle-to-grid solutions. However, there are still considerable barriers to widespread adoption of $\mathrm{P} 2 \mathrm{H}$ measures, such as insufficient collection and sharing of data required for smart building automation systems [9]. Furthermore, large scale electrification of heating can result in challenging increases in peak power demand, especially without mitigating DSM measures [10]. 
So far, the benefits of $\mathrm{P} 2 \mathrm{H}$ have been studied in a number of different power systems using various methodologies, with a lot of focus on mixed-integer and linear programming unit commitment (UC) models [5]. However, a common issue in studies explicitly modeling the residential heating demand is that the thermal dynamics of the modeled building stock are oversimplified and incapable of accurately describing the thermal flexibility of buildings, as discussed in Ref. [11]. For example, in Ref. [12], the flexibility of residential heat pumps is assumed to be directly proportionate to the deviation of the indoor temperature from a business-as-usual temperature profile, neglecting the impact of ambient conditions such as temperature and solar radiation on the heating flexibility. Similarly, the stylized heat storage approaches used in Refs. [13-15] and the constant time window for demand shifting used in Ref. [16] fail to adequately capture these effects.

Some studies have opted for simplifying the generation side instead, while accurately describing the building stock thermal dynamics using lumped capacitance models. However, using predetermined electricity prices like in Refs. [17-19] fails to account for the impact of widespread DSM measures on the prices, while merit-order models like in Ref. [20] fail to fully capture the benefits of widespread DSM due to not considering power plant start-up costs. Deterministic integrated approaches with lumped capacitance models for describing the thermal dynamics of the building stock have been successfully used to study both optimal investments and operation in a future Danish power system [21], $\mathrm{CO}_{2}$ abatement costs in a future Belgian power system [22], as well as the potential of various incentives compared to the benefits achieved using integrated optimization in the Belgian power system [23]. Nevertheless, deterministic approaches tend to achieve unrealistically optimistic results compared to stochastic models.

Finland makes an interesting case study for residential $\mathrm{P} 2 \mathrm{H}$, as electric heating is rather prominent in the residential building stock. Additionally, the building stock is relatively new and energy efficient, and the heating season is long due to the cold climate. Around $23 \%$ of all residential heating demand is covered with electric heating, with detached houses in particular accounting for roughly $70 \%$ of all electrically heated gross floor area in the Finnish building stock [24]. While there are previous Finnish case studies on the benefits of widespread $\mathrm{P} 2 \mathrm{H}$, they have either oversimplified the thermal modeling [16], or focused on specific cases such as mitigating wind power ramp effects [25] and maximizing electricity retailer revenues [26,27].

This paper aims to compare the impacts of widespread residential $\mathrm{P} 2 \mathrm{H}$ and energy efficiency improvements in a hypothetical future Nordic power system by using a stochastic integrated UC and DSM approach with lumped capacitance thermal models for describing the flexible housing stock. Residential P2H and energy efficiency improvements in the Finnish detached housing stock are considered both in an isolated Finnish power system, as well the larger Nordic power system, in order to highlight the impact of the inherent flexibility of a larger power system on the potential benefits of residential P2H solutions. Sensitivity scenarios with increasing amounts of VRE are also included to investigate the value of flexible electric heating in future renewable power systems. Finally, the heating costs of the individual houses are calculated and compared to the overall system cost savings to provide additional insight into how the energy bills of the house owners are affected.

To the authors' best knowledge, such an approach hasn't been previously used in existing literature, nor have the benefits of residential P2H and energy efficiency improvements been directly compared on a power system level. The article results corroborate the magnitude of system cost savings from building heating flexibility seen in previous studies. This is a contribution to the existing literature because the article examines a unique system setting, is based on scrupulous data collection, and has an appropriate modelling methodology.

\section{Methodology}

In order to examine the impacts of widespread residential P2H and energy efficiency measures in a future Nordic power system, the expected Finnish electrically heated detached housing stock was aggregated into two archetype houses for the Southern and Northern Finland, respectively. 
These archetype houses were assumed to sufficiently represent the aggregated behavior of the housing stock, and their thermal dynamics were described using a simple lumped capacitance model described in Section 2.3. The archetype house thermal models were implemented as an integral part of the stochastic UC optimization model called Backbone [28], briefly described in Section 2.2, that was used for rolling optimization of the power system operations with the additional $\mathrm{P} 2 \mathrm{H}$ flexibility. Finally, the benefits of different residential $\mathrm{P} 2 \mathrm{H}$ and energy efficiency improvements were examined by comparing the total yearly operational costs of the co-optimized flexible housing stock and the power system under the various power system scenarios described in Section 2.1.

\subsection{Case Studies}

The scope of the modeled hypothetical future Nordic power system in the year 2030 is presented in Figure 1. In addition to the full Nordic system case study, a separate case study for an isolated Finnish system consisting only of the power system nodes 74FI and 75FI in Figure 1 was included in order to examine the effects of residential $\mathrm{P} 2 \mathrm{H}$ and energy efficiency measures in a considerably less flexible power system. Since the detached housing stock modeling is limited to Finland, large portions of Norway and Continental Europe were heavily aggregated in order to reduce the computational load of the optimization problem for the Nordic case study.

Additional scenarios with increasing amounts of solar and wind generation capacity were included to provide insight into the dependency between VRE and the benefits of flexible electric heating. The wind and solar multiplier ranged between $0.5-2.5$ in the Nordic scenarios, and between $1-5$ in the Finland scenarios. While these are not necessarily plausible future scenarios, they nonetheless provide a way of exploring the VRE dependency of residential P2H and energy efficiency. The shares of electricity generation by fuel for all the different scenarios are presented in Tables 1 and 2. For the isolated Finland case study, the capacity of combined cycle gas turbines was increased to avoid power shortages in winter without electricity imports from the neighboring countries.

Table 1. Shares of electricity generation by fuel in the Nordic scenarios. Oil generation shares are below one per mil.

\begin{tabular}{cccccc}
\hline \multicolumn{6}{c}{ Wind \& Solar Multiplier } \\
\hline [\%] & $\mathbf{0 . 5} \times$ & $\mathbf{1 \times}$ & $\mathbf{1 . 5} \times$ & $\mathbf{2 \times}$ & $\mathbf{2 . 5 \times}$ \\
\hline Coal & 29.3 & 25.1 & 15.2 & 8.1 & 4.7 \\
Gas & 6.4 & 2.8 & 1.5 & 0.6 & 0.4 \\
Lignite & 10.2 & 3.9 & 1.7 & 0.7 & 0.3 \\
Nuclear & 8.6 & 8.6 & 8.3 & 6.7 & 5.2 \\
Biomass & 7.2 & 5.7 & 5.1 & 4.0 & 3.2 \\
Hydro & 22.4 & 22.2 & 21.7 & 22.3 & 20.2 \\
Solar & 2.6 & 5.3 & 7.7 & 9.7 & 11.6 \\
Wind & 13.2 & 26.4 & 38.7 & 47.8 & 54.4 \\
\hline
\end{tabular}

Table 2. Shares of electricity generation by fuel in the Finland scenarios. Oil generation shares are below one per mil.

\begin{tabular}{cccccc}
\hline \multicolumn{6}{c}{ Wind \& Solar Multiplier } \\
\hline [\%] & $\mathbf{1} \times$ & $\mathbf{2 \times}$ & $\mathbf{3} \times$ & $\mathbf{4} \times$ & $\mathbf{5 \times}$ \\
\hline Gas & 14.8 & 9.3 & 6.3 & 4.4 & 3.3 \\
Nuclear & 34.7 & 31.1 & 26.9 & 22.8 & 19.7 \\
Biomass & 20.8 & 18.0 & 15.7 & 13.5 & 11.3 \\
Hydro & 16.8 & 16.1 & 14.0 & 11.9 & 10.1 \\
Solar & 0.0 & 0.0 & 0.0 & 0.1 & 0.1 \\
Wind & 12.8 & 25.4 & 37.1 & 47.3 & 55.5 \\
\hline
\end{tabular}




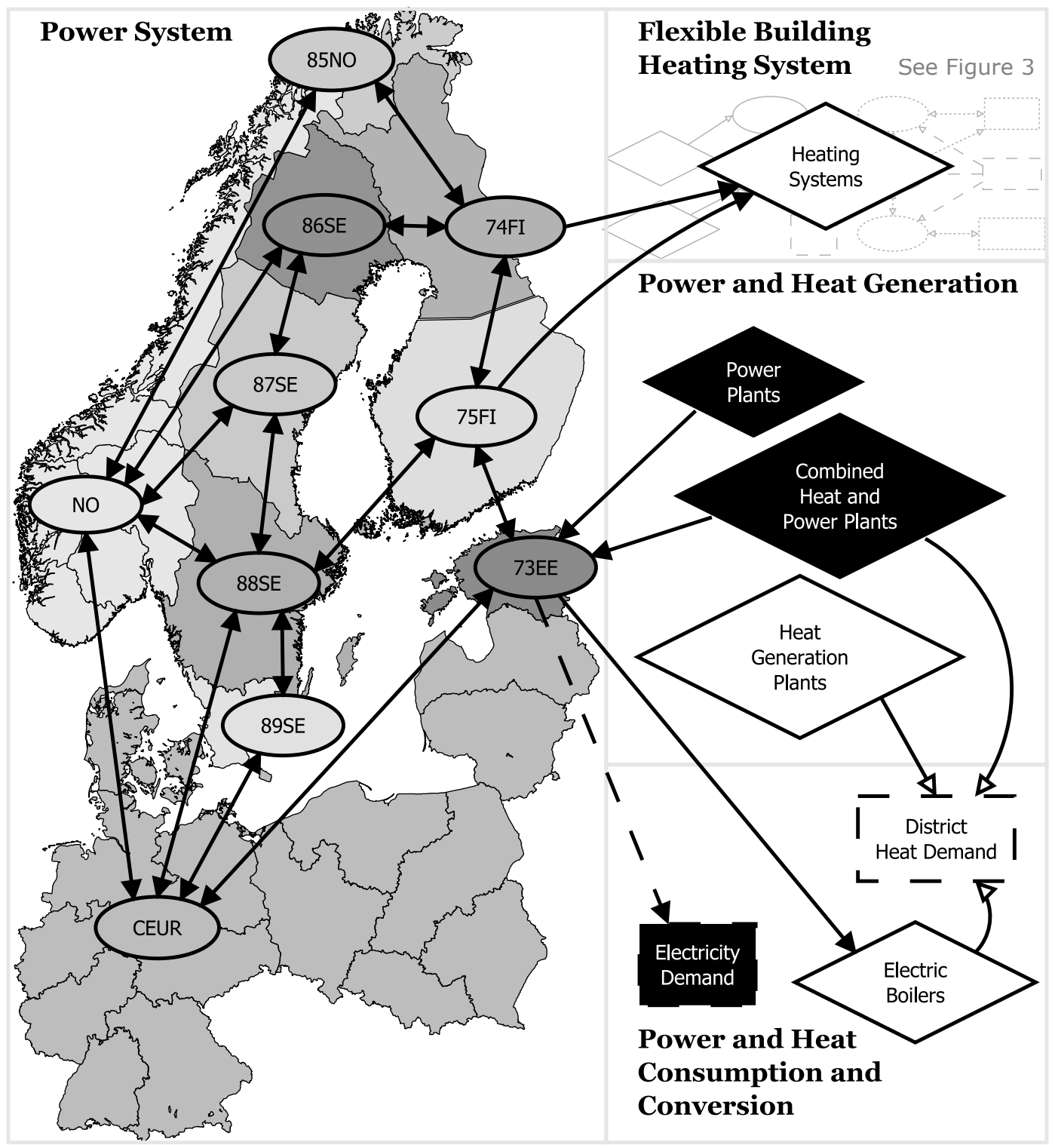

Figure 1. Illustration of the scope of the modeled power system. Ovals represent power system nodes enforcing energy and reserve balance constraints, diamonds represent units generating and consuming energy, and boxes represent exogenous energy demand. Black and white are used to indicate generation and consumption of power and heat, respectively. Every power system node has electricity and heat generation as well as demand, even though only the 73EE node is presented in detail.

Two energy efficiency refurbishment measures and three different smart electrical heating systems with increasing amounts of thermal storage were compared against each other to study the effectiveness of both energy efficiency and $\mathrm{P} 2 \mathrm{H}$ flexibility. The whole expected electrically heated detached housing stock in Finland in 2030 was included in all the scenarios, totaling 406,280 houses. In the refurbished (Rfb) energy efficiency scenarios, all of the housing stock was refurbished according to current Finnish policies [29] and national studies [30-32], reducing the heating demand by up to $37 \%$ in the older housing stock. The nearly zero-energy building (nZEB) scenarios used extreme and often prohibitively expensive refurbishments aiming to make the houses as energy efficient as modern ones, reducing the heating demand by up to $57 \%$ in the older housing stock. As for the flexible heating systems, the direct resistive heater $(\mathrm{RH})$ scenarios modeled houses with smart RHs, the storage heater (SH) scenarios modelled the houses with smart SHs, and the super storage heater (SSH) scenarios used hypothetical 
heaters with three times the heat capacity of a regular SH. All of the modeled flexible heating systems included smart domestic hot water (DHW) storage tanks as well.

The power system data was primarily based on the results of the European Reference Scenario 2016 [33], the e-Highway 2050 project [34], and the Ten Year Network Development Plan 2016 [35]. All time series data was obtained for the year 2013 whenever possible, but compromises had to be made with hydropower inflow and district heating demand time series. Since hydropower inflow time series from 2013 were unavailable, time series from 2012 were used instead. Similarly, district heating demand time series for the modeled power system were unavailable, and the district heating demand profiles were based on the electricity demand time series from the Ten Year Network Development Plan 2016 market modeling data. See Appendix A for more details on the various power system data sources and assumptions. The state of the residential housing stock in the year 2030 was based on national modeling results about the future development of the Finnish residential building stock [36,37]. See Appendices $B$ and $C$ for more details on the properties of the housing stock and heating system parameters, respectively.

\subsection{Power System Modeling}

As widespread residential $\mathrm{P} 2 \mathrm{H}$ and energy efficiency improvements potentially affect the way power systems are operated, the power system was modeled explicitly in order to capture the impact of the flexible detached housing stock. In this work, the co-optimization of the flexible housing stock and the power system was carried out using an open source generic energy network stochastic optimization model called Backbone [28], currently under development with a publication forthcoming. Backbone is a stochastic mixed-integer linear programming model with an emphasis on model adaptability. Many of the model equations are formulated to be as generic as possible, allowing them to be used for different applications simply by changing the model input parameters, such as the generic energy balance constraint presented in Equation (1). Similarly, the default objective function aiming to minimize the expected system costs presented in Equation (2) can be easily changed depending on the desired application. The stochastic time structure can also be configured for different purposes besides the rolling unit commitment and dispatch optimization in this work, such as investment planning or building energy management optimization. The version of Backbone used for this work has been tagged as "RealValue_ArticleResults" in the model repository [28].

Figure 1 presents an illustration of the energy network structure within Backbone used in this work, with a generic energy balance constraint

$$
\begin{aligned}
& p_{n}^{\text {energyCapacity }}\left(v_{n, f, t}^{\text {state }}-v_{n, f, t-1}^{\text {state }}\right)=\left(-p_{n}^{\text {selfDischargeLoss }} v_{n, f, t}^{\text {state }}\right. \\
& +\sum_{n^{\prime} \in \mathbf{N}_{n}}\left[p_{n, n^{\prime}}^{\text {diffCoeff }}\left(v_{n^{\prime}, f, t}^{\text {state }}-v_{n, f, t}^{\text {state }}\right)\right. \\
& \left.+\left(1-p_{n^{\prime}, n}^{\text {transferLoss }}\right) v_{n^{\prime}, n, f, t}^{\text {transer }}-v_{n, n^{\prime}, f, t}^{\text {transfer }}\right] \\
& \left.+\sum_{u \in \mathbf{U}_{n}}\left[ \pm v_{n, u, f, t}^{\text {generation }}\right]-v_{n, f, t}^{\text {spill }} \pm \tau_{n, f, t}^{\text {influx }}\right) \Delta_{t} \\
& \forall\{n, f, t\}
\end{aligned}
$$

enforced at each node $n$ for all forecasts $f$ and time steps $t$. The set $\mathbf{N}_{n}$ contains all nodes $n^{\prime}$ connected to node $n$ via energy transfer variables or diffusion coefficients, and the set $\mathbf{U}_{n}$ contains all units $u$ connected to node $n$. Depending on the purpose of each node $n$, the different parameters $p$, variables $v$, and time series $\tau$ can have different interpretations and measurement units, and are fixed to zero when not applicable. The energy Capacity parameter converts the energy content of the state variable into the desired energy unit, while the selfDischargeLoss and diffCoeff parameters determine the self-discharge and energy diffusion rates respectively. The transferLoss parameter represents the energy losses when transferring energy to this node from connected nodes via the transfer variable, 
and the spill variable represents transferring energy out of the model boundaries. The generation variable represents energy generation and consumption by different units, and the influx time series represents uncontrollable energy gains and demand. The generation variable and the influx time series are included using \pm for clarity, as their nature changes depending on the application. The $\Delta_{t}$ parameter represents the length of time step $t$, and is measured in hours. The presented Equation (1) has been simplified from its full formulation [28] for clarity by dropping the grid index, using symmetrical diffCoeff parameters, and dropping the dummy variables ensuring constraint feasibility.

The power system nodes were subject to the energy balance constraint presented in Equation (1), with the exception that they had no state variables, essentially reducing the equation to a power balance constraint instead. Power system nodes were not allowed to use the spill variable to dump excess electricity, and the influx time series was used to represent inflexible electricity demand in $\mathrm{MW}_{e}$. Similarly, the generation and transfer variables were measured in $\mathrm{MW}_{e}$ for the power system nodes. For hydropower reservoir nodes, the state variables represented the amount of electrical energy stored within the reservoir nodes as water in $\mathrm{MWh}_{e}$, the influx time series defined the energy inflow into the reservoir nodes in $\mathrm{MW}_{e}$, and the spill variable enabled spilling of excess energy in $\mathrm{MW}_{e}$ if necessary. Run-of-river hydropower was simply modeled using a capacity factor time series based on water inflow data that the power plants could either utilize or not.

Constraints to limit the electricity and reserve transfer capacities between the power system nodes were also implemented. Furthermore, a number of different constraints were used to ensure realistic unit operation, such as conversion efficiencies, combined heat and power production ratios, and reserve provision. However, while the units were modeled with startup, shutdown, and online variables, these were relaxed into continuous variables in order to avoid turning the LP problem into a computationally more demanding mixed-integer problem. While a comprehensive model documentation of Backbone is not yet available, the implementation of the various constraints is available through the model repository [28].

The full-year optimization employed a moving horizon, where only the first six realized hourly time steps were recorded for each solving process, before the model advanced six hours in time for another solving process. Reserve commitments were fixed one solving step ahead of time based on the imperfect information in the forecast branches, as illustrated in Figure 2. Due to the importance of reservoir hydropower in the Nordic power system, the modeling horizon was extended to cover three years in order to achieve more realistic use of the hydropower reservoirs. All time series data was simply repeated for the consecutive years to avoid undesired hoarding or dumping of reservoir hydropower. The time steps were heavily aggregated for all but the earlier time steps in each solving process to keep the computational load feasible with such a long modeling horizon, as indicated in Figure 2.

The optimization included three forecast branches, as illustrated in Figure 2, out of which only the central forecast spanned the entire two-year modeling horizon in order to reduce the computational load of the model. The optimistic forecast used higher capacity factors, hydropower inflows and higher ambient temperatures, with lower electricity and district heating demands, while the pessimistic forecast used the opposite. The wind power and ambient temperature forecasts were based on data from the European Centre for Medium-Range Weather Forecasts, and and represent the 20\%, 50\% and $80 \%$ quantiles of 51 ensemble forecast members. For other forecasts, the central forecast was the same as the realization, while the optimistic and pessimistic forecast branches assumed a fixed error of $20 \%$ for photovoltaic panel capacity factors, and $5 \%$ for hydropower inflows, electricity demand, and district heating demand. 


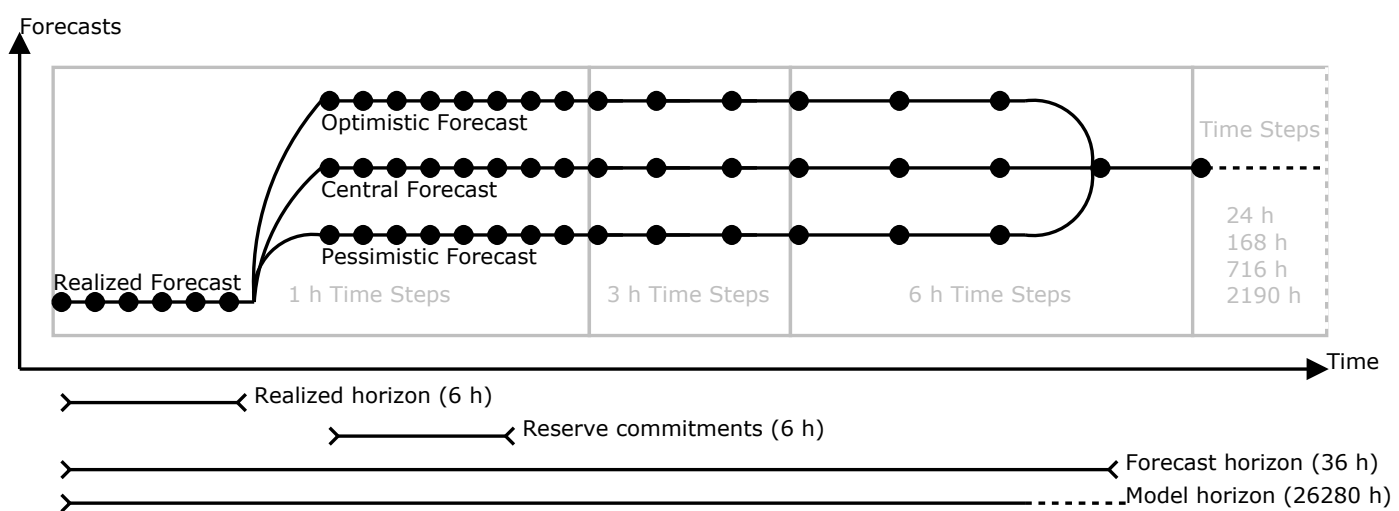

Figure 2. Illustration of the forecast-time structure of a single solving process used for the moving horizon power system optimization. The dots in the tree depict individual forecast-time steps, and represent longer periods of time the further they are located in the modeling horizon. Reserve commitments were locked one solving step ahead of time based on the imperfect information in the forecast branches, which converge into the central forecast at the end of the forecast horizon to reduce computational load.

The objective of the power system optimization was to minimize the expected operational system costs described by the objective function

$$
\begin{aligned}
v^{\text {objective }}= & \sum_{f, t}\left[p _ { f , t } ^ { \text { probability } } \left(\sum _ { n , u } \left[c_{u}^{\text {startup\&emission }} v_{u, f, t}^{\text {startup }}\right.\right.\right. \\
& \left.\left.\left.+\left(c_{u}^{\text {O\& } M_{v} \text { generation }}+\sum_{n, u, f, t}\left[c_{u, F}^{\text {fuel\&emission }} v_{u, F, f, t}^{\text {fueluse }}\right]\right) \Delta_{t}\right]\right)\right] \\
& +\sum_{n \in \mathbf{N}_{w}}\left[p^{\text {reservoirValue }}\left(v_{n, f, t^{\prime}}^{\text {state }}-v_{n, f, t^{\prime \prime}}^{\text {state }}\right)\right]
\end{aligned}
$$

over all forecasts $f$ and time steps $t . \mathbf{F}_{u}$ is the set of fuels for unit $u, \mathbf{N}_{w}$ is the set of hydropower reservoir nodes, and the time indexes $t^{\prime}$ and $t^{\prime \prime}$ refer to the first and last time steps of the current solving process, respectively. Both the optimistic and pessimistic forecasts were assigned a probability parameter of $20 \%$, while the probability of the central forecast was designated as $60 \%$ until the forecast horizon, and $100 \%$ for the later time steps. The startup variable represented unit start-ups, and the fuelUse variable represented the consumption of fuel energy content of the units in $\mathrm{MW}_{F}$. As for the different cost parameters $c$, the startup\&emission cost parameter contained all the fuel, emission, and operation and maintenance (O\&M) costs related to unit startups in EUR/start-up, while these costs were divided into the $O \& M$ and fuel\&emission cost parameters during normal unit operation

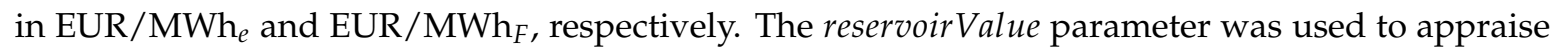
the change in the stored electricity content of the hydropower reservoirs in EUR/MWh $\mathrm{MV}_{e}$ over the three-year modeling horizon, and was based on the yearly average marginal cost of generation for each scenario. See Appendix A for details on the sources of the cost terms. For clarity, the presented Equation (2) has been simplified from its full formulation [28] by combining different fuel and emission related cost parameters, as well as by dropping the grid index, unused investment and node slack variable cost terms, and penalty terms for energy and reserve provision dummy variables.

\subsection{Housing Stock Thermal Modeling}

A simplified description of the housing stock is required to effectively represent numerous detached houses over large geographical areas within power system models. In this work, the expected future electrically heated Finnish detached housing stock was aggregated into two archetype houses for the Northern and Southern Finland, respectively. The properties of the archetype houses were 
calculated as a gross floor area weighted average of the expected future electrically heated detached housing stock over the different municipalities and house age categories. Similarly, the weather data for the archetype houses was aggregated by calculating the gross floor area density weighed average over the desired regions. For simplicity, the archetype houses were assumed to be rectangular in shape and aligned perpendicular to the cardinal directions, as reliable data on the typical shapes and alignments of Finnish detached houses were not available. Furthermore, the space heating and ventilation systems were assumed to be sufficiently distributed to provide uniform heating and ventilation to the whole archetype house, avoiding the need for multi-zone modeling approaches. See Appendix B for more information on the aggregation of the Finnish detached housing stock.

The archetype houses were assumed to sufficiently represent the thermal dynamics of the Finnish electrically heated detached housing stock, as well as its flexibility. A simple lumped capacitance model, illustrated in Figure 3, was used for describing the dynamics of the archetype houses. The model used three temperature nodes for the house interior and envelope, one temperature node for the DHW storage tank, and an extra temperature node for $\mathrm{SH}$ and $\mathrm{SSH}$ systems in their respective scenarios. The archetype houses were included as an integral part of the larger power system model, and the generic energy balance equality constraint in Equation (1) was used for implementing the lumped capacitance house thermal model as follows: The energy Capacity parameter described the heat capacity of the thermal node $n$ in $\mathrm{Wh} / \mathrm{K}$, the state variable recorded the temperature of $n$ in kelvin, and the diffCoeff parameter defined the heat transfer coefficient between the nodes $n$ and $n^{\prime}$ in $\mathrm{W} / \mathrm{K}$. The selfDischargeLoss parameter described the heat losses from the DHW tank that were assumed not to affect the house thermal nodes via heat transfer in $\mathrm{W} / \mathrm{K}$. The transfer variable and the transferLoss parameter represented controlled heat release in W and its efficiency from the modeled SHs and SSHs into the house interior, while the generation variable described the conversion of electricity into heat within the SHs, DHW tanks, and RHs in W. Additionally, the generation variable described cooling the house interior using an air conditioner. The influx time series applied internal and solar heat gains for the house interior and envelope nodes, as well as DHW consumption for the DHW tank node, all in W. None of the temperature nodes were permitted to use the spill variable to dump excess heat. When connecting the archetype house lumped capacitance models into the power system nodal network, the aggregated power consumption of the heating equipment in $\mathrm{MW}_{e}$ was calculated simply by multiplying the power consumption of the archetype house by the number of houses it was used to represent.

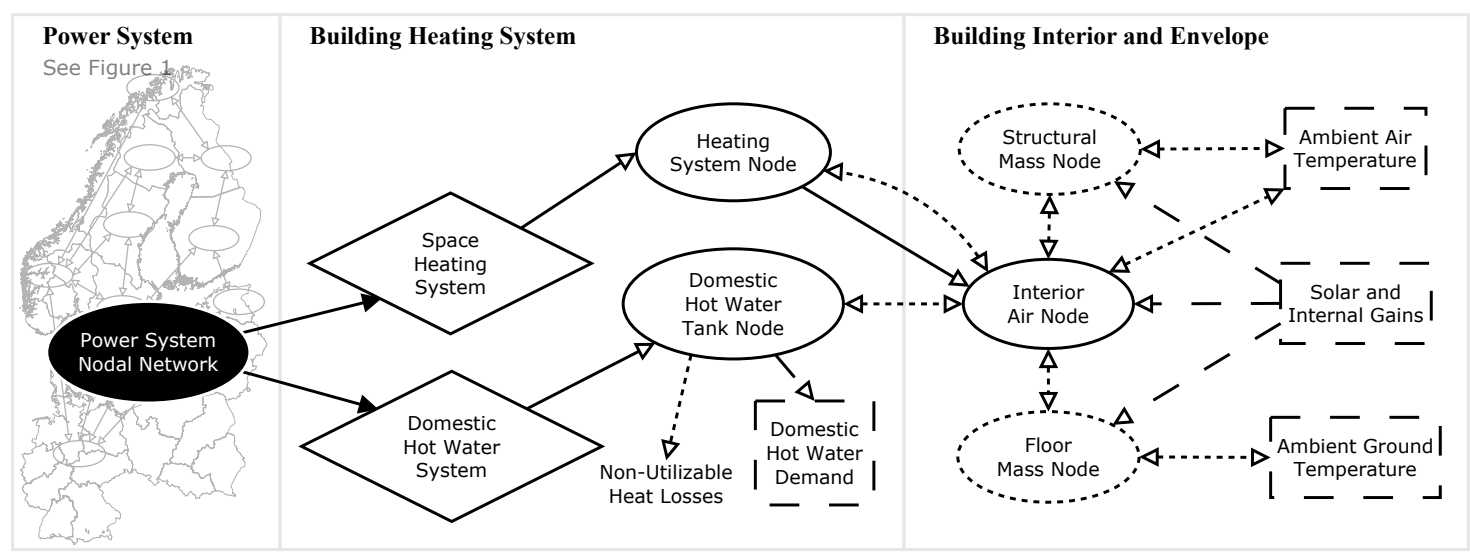

Figure 3. Illustration of the lumped capacitance model used for describing the thermal dynamics of the detached housing stock. Ovals represent temperature nodes and enforce energy balance constraints, diamonds represent units converting power to heat, and boxes represent exogenous heat demand, heat gains, and ambient temperatures. Solid lines represent controlled transfer and conversion of energy, dotted lines represent diffusion of energy, and dashed lines represent exogenous energy demand and gains. 
Besides the energy balance constraint presented in Equation (1), most of the other constraints applied to the lumped capacitance model were rather straightforward. The temperature of the interior air node was constrained between $21-27^{\circ} \mathrm{C}$ based on national guidelines [38], the temperature of the DHW tank was constrained between $60-80^{\circ} \mathrm{C}$ in order to ensure availability of hot water, and the permitted temperature of the $\mathrm{SHs}$ was constrained between $30-580^{\circ} \mathrm{C}[39]$ to ensure heating availability. The parameters for the lumped capacitance models of the archetype houses, as well as internal and solar gains, were calculated mainly according to EN ISO 13790 [40], other standards [41,42], as well as national guidelines [43,44]. See Appendix $C$ for more details on the house thermal model and heating system parameters.

The performance of the lumped capacitance house thermal model was verified against IDA Early Stage Building Optimization (ESBO) v1.13 [45], which is a free building simulation program based on IDA Indoor Climate and Energy (ICE) with limited functionality. The lumped capacitance model archetype houses were matched with the IDA ESBO default single and two story detached houses as closely as possible, and simulated using weather data from both Helsinki Airport $\left(60^{\circ} 19^{\prime} 01^{\prime \prime} \mathrm{N}\right.$, $24^{\circ} 58^{\prime} 01^{\prime \prime}$ E) and Inari town center $\left(68^{\circ} 54^{\prime} 18^{\prime \prime} \mathrm{N}, 27^{\circ} 01^{\prime} 49^{\prime \prime} \mathrm{E}\right)$ for the years $2011-2012$, in order to ensure consistent model performance in both Southern and Northern Finland. Similarly, the detached housing stock aggregation methodology was verified by calculating the yearly heating demand of the detached housing stock using different numbers of archetype houses and regional divisions, and comparing the results to national statistics [24] for the years 2010-2013.

\section{Results}

Full-year integrated optimization of the flexible electrically heated Finnish detached housing stock and power system operations was performed for all the different scenarios detailed in Section 2.1 to study the benefits of various residential $\mathrm{P} 2 \mathrm{H}$ and energy efficiency measures. The resulting total yearly system costs were used for comparing the system benefits of each studied flexible heating system and energy efficiency measure. Additionally, the resulting marginal costs of generation were used for studying the impacts of widespread residential P2H and energy efficiency measures on electricity prices and the yearly heating costs of individual house owners.

The results of each scenario were compared against a conventional direct electrical heating baseline, assumed to be included in the total electricity consumption in the power system nodes 74FI and 75FI in Figure 1. For the P2H and energy efficiency scenarios, the baseline heating electricity consumption was calculated by minimizing the heating electricity consumption of the modelled detached housing stock separately from the power system. This baseline was then subtracted from the total electricity consumption time series of the corresponding power system node before the flexible housing stock was co-optimized as a part of the power system.

In order to estimate the impact of widespread $\mathrm{P} 2 \mathrm{H}$ and energy efficiency for individual house owners, the marginal heating costs per house were calculated based on the marginal costs of generation and the electricity consumption of the modeled heating equipment. Thus, the estimated yearly heating costs don't include other common cost components of retail electricity prices, such as taxes or transmission tariffs. It is also important to note that the objective function only aimed to minimize the total system costs, and the heating costs were calculated to show how end-user energy costs were affected.

\subsection{Nordic Case Study}

Table 3 contains the total system costs and heating costs for the baseline of the different wind and solar multiplier scenarios, used for calculating the system cost savings and heating cost savings for the different $\mathrm{P} 2 \mathrm{H}$ and energy efficiency scenarios presented in Figure $4 \mathrm{a}, \mathrm{b}$. The $\mathrm{RH}$ scenarios achieved the lowest system cost savings of Figure 4a, while the increased thermal storage capacities of SH and $\mathrm{SSH}$ resulted in slightly higher savings in their respective scenarios. The savings were seen to increase along with the amount of VRE up until 2-2.5 times the expected amount, and then begin to stagnate. 
The Rfb and nZEB energy efficiency scenarios achieved noticeably higher system cost savings in Figure $4 \mathrm{~b}$ than the flexible heating system scenarios with low amounts of VRE. However, the savings achieved with energy efficiency improvements steadily declined as the amount of VRE was increased, with the SH and SSH scenarios achieving higher savings than the Rfb scenario with 2-2.5 times the expected amount of VRE. Combining smart RH systems with energy efficiency improvements further increased the system cost savings of the energy efficiency measures in the Rfb $+\mathrm{RH}$ and nZEB $+\mathrm{RH}$ scenarios, although these additional savings were slightly lower than the savings in the RH scenario.

Table 3. Baseline costs for the different wind and solar multiplier scenarios in the Nordic case study.

\begin{tabular}{ccc}
\hline VRE & System Cost (MEUR/Year) & Heating Cost (EUR/House/Year) \\
\hline $0.5 \times$ & 42,617 & 1906 \\
$1 \times$ & 32,660 & 1632 \\
$1.5 \times$ & 24,765 & 1330 \\
$2 \times$ & 19,856 & 834 \\
$2.5 \times$ & 16,970 & 682 \\
\hline
\end{tabular}

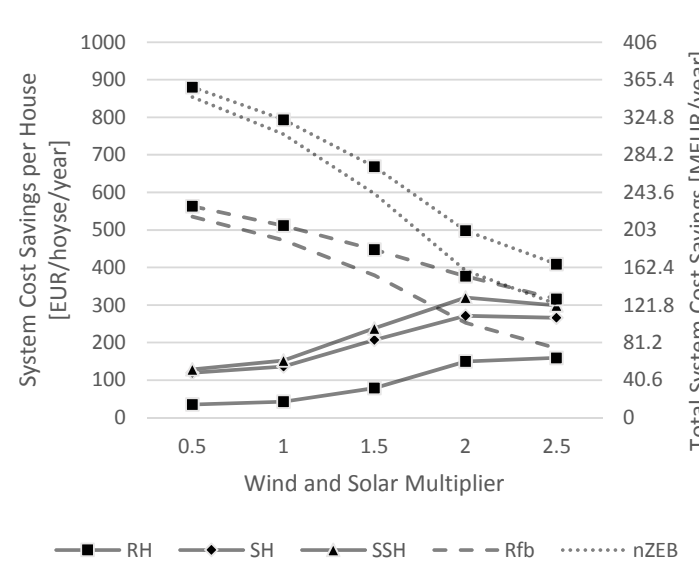

(a)

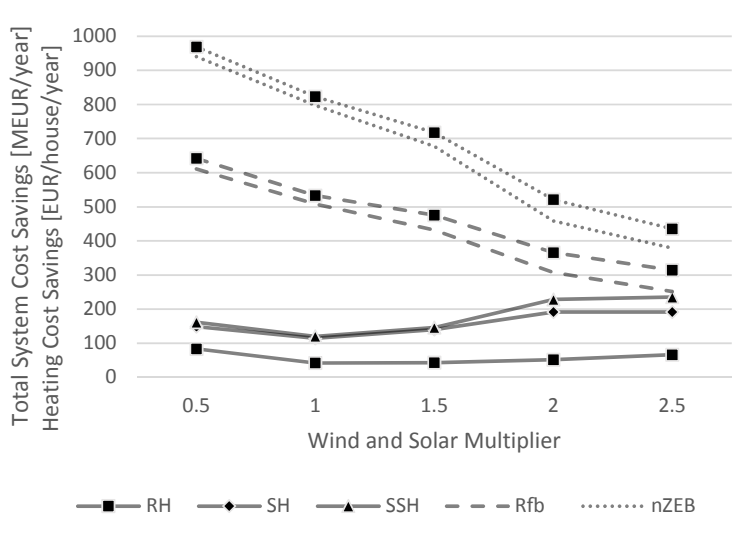

(b)

Figure 4. System cost savings (a) and heating cost savings (b) for the Nordic case study for the different energy efficiency ( $\mathrm{Rfb}, \mathrm{nZEB})$ and heating flexibility ( $\mathrm{RH}, \mathrm{SH}, \mathrm{SSH})$ scenarios. The wind and solar multiplier was used to increase the amount of variable renewable energy in the modelled system.

The RH scenario also achieved the lowest heating cost savings in Figure $4 \mathrm{~b}$, while the additional thermal storage capacity of the SH and SSH achieved slightly higher savings. Interestingly, the heating cost savings were higher in the $0.5 \times$ VRE scenario than in the $1 \times$ and $1.5 \times$ scenarios for all of the flexible heating systems. Similar to the system cost savings, the heating cost savings began to stagnate between 2-2.5 times the expected amount of VRE. Overall, the heating cost savings of the flexible heating systems were slightly lower than the respective system cost savings with 1-2.5 times the expected amount of VRE.

The energy efficiency scenarios in Figure $4 \mathrm{~b}$ achieved noticeably higher heating cost savings than the flexible heating system scenarios, especially at low amounts of VRE. Unlike the P2H systems, the energy efficiency measures achieved higher heating cost savings than system cost savings. Again, combining a smart RH system into the energy efficiency improvements in the Rfb $+\mathrm{RH}$ and $\mathrm{nZEB}+\mathrm{RH}$ scenarios slightly increased the achieved heating cost savings compared to the Rfb and nZEB scenarios.

The impact of widespread flexible heating on the marginal costs of generation were found to be more noticeable at higher costs and larger amounts of VRE, as shown in Figure 5. The residential P2H systems can be seen to shift consumption away from expensive hours and towards cheap ones, while the energy efficiency measures simply shift the duration curve to the left, resulting in slightly lower prices overall. 


\subsection{Finland Case Study}

Table 4 contains the baseline costs used for calculating the system and heating cost savings presented in Figure $6 \mathrm{a}, \mathrm{b}$ for the Finland case study. Similar to the Nordic case study, the RH system achieved the lowest system cost savings in Figure 6a, while the SH and the SSH achieved noticeably higher savings due to their increased thermal storage capacity. The savings of the flexible heating systems were seen to increase along with the amount of VRE in the power system up to around 2-3 times the expected amount in 2030. However, when the amount of VRE was increased even further, the benefits of the flexible heating systems turned into a slight decline.

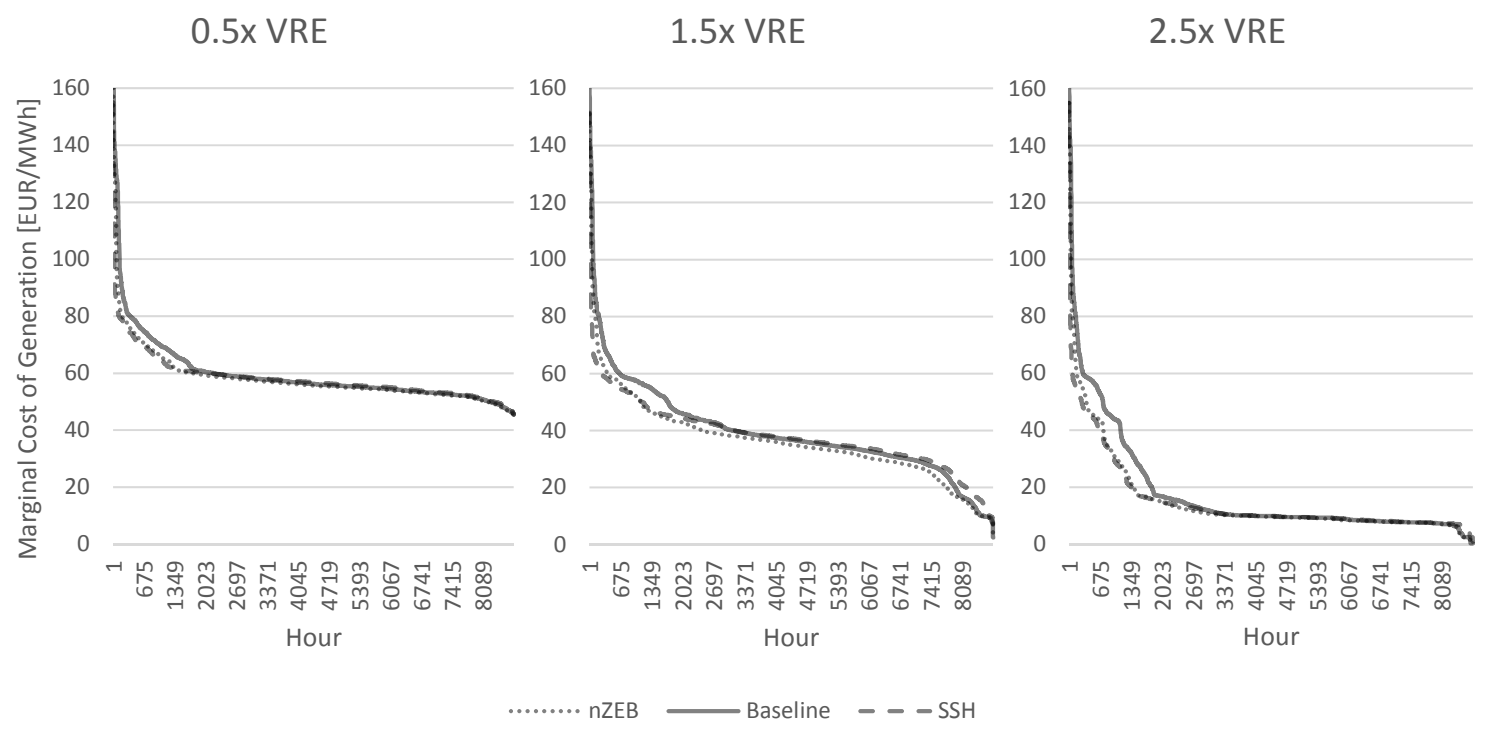

Figure 5. Duration curve for the marginal cost of generation for the $0.5 \times, 1.5 \times$ and $2.5 \times$ solar and wind multiplied scenarios for the Southern Finland power system node 75FI in the Nordic case study. The nZEB and SSH scenarios are shown in order to illustrate the potential effects of widespread energy efficiency and flexibility measures on the electricity prices.

Table 4. Baseline costs for the different wind and solar multiplier scenarios in the Finland case study.

\begin{tabular}{ccc}
\hline VRE & System Cost (MEUR/Year) & Heating Cost (EUR/House/Year) \\
\hline $1 \times$ & 2982 & 1710 \\
$2 \times$ & 2634 & 1258 \\
$3 \times$ & 2368 & 955 \\
$4 \times$ & 2176 & 769 \\
$5 \times$ & 2033 & 635 \\
\hline
\end{tabular}

The energy efficiency measures resulted in somewhat higher system cost savings than $\mathrm{P} 2 \mathrm{H}$ in Figure 6a with low amounts of VRE, but declined along with the increase in VRE. The Rfb scenario only achieved more savings than the SH and SSH scenarios in the $1 \times$ VRE scenario, while the nZEB scenario remained more beneficial than the $\mathrm{SH}$ and $\mathrm{SSH}$ scenarios until 3-4 times the expected amount of VRE. The energy efficiency savings were further improved with smart RH in the Rfb $+\mathrm{RH}$ and nZEB + RH scenarios, increasing their savings to the level of the SSH scenario and beyond. Compared to the simple energy efficiency savings in the Rfb and nZEB scenarios, the additional savings achieved via the flexible $\mathrm{RH}$ in the $\mathrm{Rfb}+\mathrm{RH}$ and $\mathrm{nZEB}+\mathrm{RH}$ scenarios were slightly lower than in the regular RH scenarios.

Compared to the system cost savings, the heating cost savings presented in Figure $6 \mathrm{~b}$ of the flexible heating systems are noticeably lower. The RH system ended up with slightly increased heating costs in the 1-3× VRE scenarios, while the SH and SSH scenarios managed to achieve increasing savings. Interestingly, the bought energy savings for the flexible heating systems were seen to increase 
along with the amount of VRE even beyond the 2-3 times the expected amount, unlike the system cost savings.

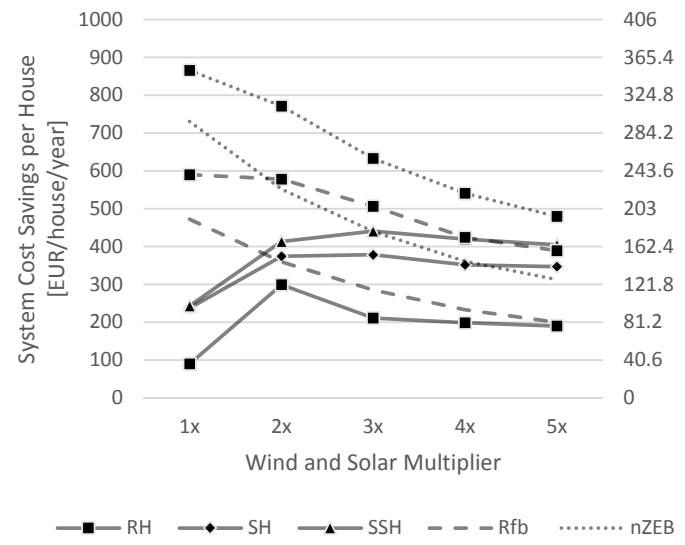

(a)

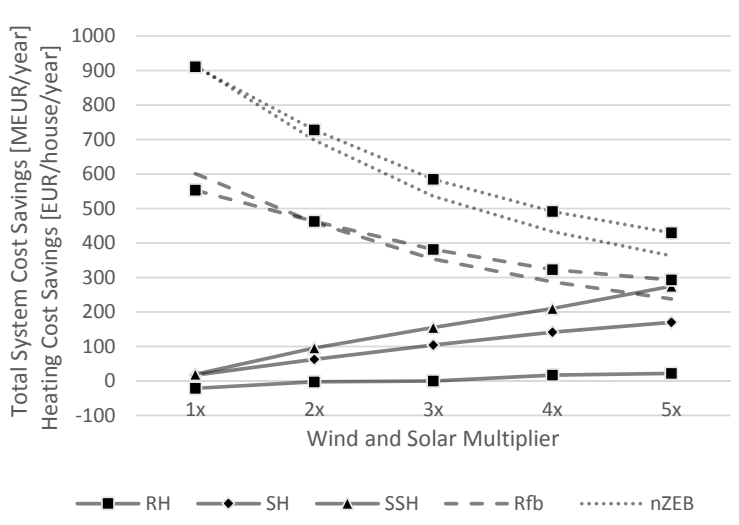

(b)

Figure 6. System cost savings (a) and heating cost savings (b) for the Finland case study for the different energy efficiency (Rfb, nZEB) and flexible heating ( $\mathrm{RH}, \mathrm{SH}, \mathrm{SSH}$ ) scenarios. The wind and solar multiplier was used to increase the amount of variable renewable energy in the system.

Similar to the Nordic case study, the energy efficiency scenarios in Figure $6 \mathrm{~b}$ achieved higher heating cost savings than system cost savings, and the savings decreased as the amount of VRE was increased. The $\mathrm{Rfb}+\mathrm{RH}$ and $\mathrm{nZEB}+\mathrm{RH}$ scenarios resulted in additional heating costs with $1 \times \mathrm{VRE}$, but yielded additional savings with higher amounts of VRE, similar to the regular RH scenario.

The widespread deployment of flexible heating systems was seen to have a noticeable impact on the marginal cost of generation in the Finland case study, as illustrated in Figure 7. As expected, the additional flexibility was seen to shift consumption from hours of expensive prices to cheaper ones, whereas energy efficiency could be seen to simply lower the prices throughout the year. Increasing the amount of VRE could also be seen to significantly reduce the amount of mid-range prices, while the peak prices remained relatively unchanged.

1x VRE

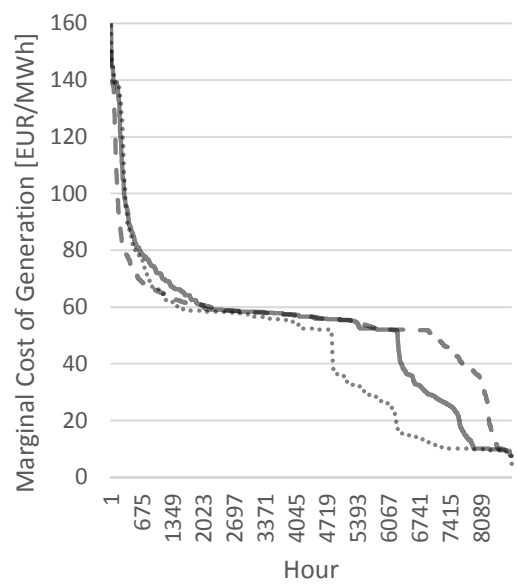

3x VRE

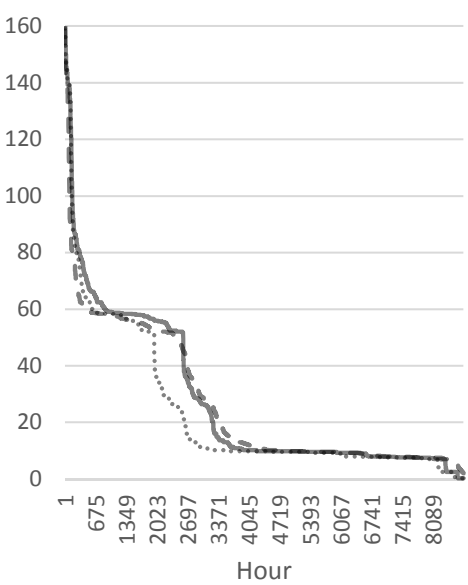

5x VRE

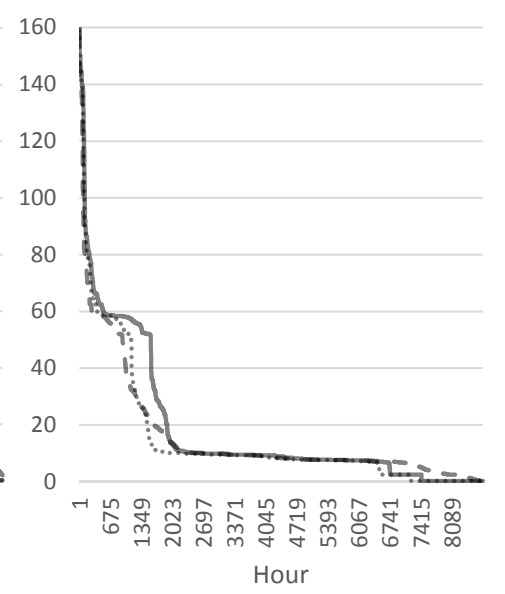

Figure 7. Marginal cost of generation for the $1 \times, 3 \times$ and $5 \times$ wind and solar multiplied scenarios for the Southern Finland power system node 75FI in the Finland case study. The nZEB and SSH scenarios are shown in order to illustrate the effect of widespread energy efficiency and flexibility measures on the electricity prices. 


\section{Discussion}

Overall, the system cost results agree relatively well with existing literature. The total operational system cost savings of around 12-28 MEUR/year of the entire electrically heated Finnish building stock in Ref. [16] agree well with the 14-65 MEUR/year achieved in the RH scenarios of the Nordic case study, although the detached housing stock modeled in this work only covers around $70 \%$ of the whole electrically heated Finnish building stock. Similarly, the resulting yearly operational system costs of the Finland case study agree relatively well with the corresponding value of 3620 MEUR/year in Ref. [16], considering the different data sources and assumptions. Most relevant studies, however, have focused on studying the impacts of residential P2H with heat pumps [11,12,20,21], often as an alternative to fossil fuel based heating systems. Considering the better coefficient of performance of air source heat pumps in more southern countries and the difference in the amount of modeled houses, the system cost savings around 200 EUR/house/year in Ref. [20] for a million detached houses in Belgium agree relatively well with the savings between 90-300 EUR/house/year achieved in the RH scenarios of the Finland case study. Similarly, the 36-47 MEUR/year for 1,260,202-1,758,774 houses in Germany [12], again with air source heat pumps, are also quite similar to the 36-122 MEUR/year achieved in the isolated Finland RH scenarios.

From the power system's point of view, the modeled energy efficiency improvements yielded larger system cost savings than P2H with lower amounts of VRE. However, the system cost savings of $\mathrm{P} 2 \mathrm{H}$ were seen to increase along with the amount of VRE in the system similar to previous studies [12,20], and eventually SHs were seen to become more valuable to the system than simple energy efficiency refurbishments. This gives credence to a hypothesis that there is a potentially important trade-off between heating flexibility and energy efficiency in buildings-both current policy goals in European Union. Interestingly, the system cost savings of flexible heating systems turned into a decline as more VRE was added to the system, seen between 2-3 times the expected wind and solar generation capacity in 2030 in both case studies. This was most likely due to the decrease in electricity prices seen in Figures 5 and 7, leaving less valuable price arbitrage for the $\mathrm{P} 2 \mathrm{H}$ to exploit. Similarly, this caused the decline in system cost savings of energy efficiency improvements. However, the relative system cost savings of $\mathrm{P} 2 \mathrm{H}$ were still seen to increase at 3-5 times the expected amount of VRE, although at a noticeably slower rate. It should be noted that a large increase in VRE would result in changes in the rest of the generation portfolio over time, and could potentially increase the system cost savings of flexible heating systems.

The system cost savings achieved by the different flexible heating systems were found to increase along with the amount of thermal storage in both case studies. While the SHs achieved noticeably higher savings than the RHs, further increasing the size of thermal storage in the SSH scenarios only achieved around 2-19\% higher system cost savings than the SHs even with three times the storage capacity. It would seem that the main benefit of residential $\mathrm{P} 2 \mathrm{H}$ with thermal storage lies in decoupling the heating demand from the electricity demand, as opposed to storing heat for prolonged periods of time.

Overall, the inherent flexibility of a larger power system in the Nordic case study resulted in a more balanced system and heating cost savings compared to the isolated Finland case study. In most of the scenarios, the system cost minimization also decreased the household heating costs. However, the 1-3× VRE RH scenarios of the Finland case study resulted in increased heating costs for the house owners. This increase can be explained by excessive use of the heating flexibility due to high demand from the power system side, resulting in increased heating energy consumption due to the poor heat storage in the houses' thermal mass. A similar effect could explain the decrease in heating cost savings between $0.5-1 \times$ VRE scenarios in the Nordic case study, with the increased demand for flexibility resulting in the heating systems servicing the power system against the interests of the house owner. While the system cost savings of P2H were higher in the isolated Finland case study than in the Nordic case study, it would seem that the better system performance was achieved at least partly at the house owners' expense. 
Compared to the median heating cost savings of 72 EUR/house/year and 23 EUR/house/year for years with high and normal electricity prices respectively in a heating cost minimization DSM study with Swedish electrically heated detached houses [18], the heating cost savings in the RH scenarios between 42-83 EUR/house/year and between -22-22 EUR/house/year in the Nordic and Finland case studies respectively agree surprisingly well despite the different objective. However, considering the full heating cost saving ranges of 0.9-330 EUR/house/year for high prices and 0.36-97 EUR/house/year for normal prices in Ref. [18], there is a potential conflict of interest between the objectives of the power system and the house owners. Additionally, this conflict of interest seems to become more pronounced for isolated power systems where flexibility is in shorter supply.

The energy efficiency improvements resulted in consistently higher heating cost savings for the house owners, as well as comparable system cost savings in most scenarios. Additionally, the savings with flexible heating systems were seen to decrease only slightly in the Rfb $+\mathrm{RH}$ and nZEB $+\mathrm{RH}$ scenarios when combined with energy efficiency improvements. Considering that the energy efficiency improvements reduce other components of retail electricity prices besides the price of energy, e.g., transmission tariffs and energy taxes, the actual heating cost savings for energy efficiency improvements are likely to be even higher than the energy-only costs presented in this work. Conversely, transmission tariffs and energy taxes have a slightly negative impact on the heating cost savings of $\mathrm{P} 2 \mathrm{H}$, as storing heat always results in some extra energy consumption. However, it is worth noting that the simulations were calculated with $100 \%$ of the expected direct electrically heated houses in Finland participating in $\mathrm{P} 2 \mathrm{H}$, resulting in significantly lower system cost savings per house than for lower penetrations [20,39]. The savings achieved via energy efficiency improvements, on the other hand, are most likely more independent from their penetration in the building stock, although this could depend on the composition of the generation portfolio. Thus, the system cost savings per house for lower penetrations of flexible heating systems could be more competitive with the energy efficiency improvements.

One potential benefit of residential P2H over simple energy efficiency is that it could increase the profitability of VRE generation capacity investments, making high VRE penetrations economically more feasible. However, capturing such effects would require modeling endogenous investments at least on the power system side, and potentially even for residential P2H capacity [21] or energy efficiency improvements. With reliable information about the investment costs related to flexible heating systems and energy efficiency improvements, a proper comparison between the two using cost-benefit analysis would be an interesting future research pathway.

\section{Conclusions}

Widespread residential DSM can have significant impacts on the operation of power systems, permitting them to operate more efficiently at a lower cost. With sufficient amounts of VRE in the power system, residential $\mathrm{P} 2 \mathrm{H}$ solutions with thermal storage can yield more savings than improvements into building energy efficiency. While flexible storage heaters were found to yield significantly higher savings than flexible direct resistive heating, further increasing the amount of thermal storage proved ineffective even with significant amounts of VRE in the power system. However, the study did not consider changes in the generation portfolio. With increasing VRE, base generation capacity would likely decrease and peak generation capacity increase, potentially resulting in improved economics for larger residential thermal storages. Comparing the benefits of residential $\mathrm{P} 2 \mathrm{H}$ and energy efficiency improvements while taking into consideration investments into different types of generators presents an interesting future research possibility. Furthermore, reliable information about the investment costs of the different $\mathrm{P} 2 \mathrm{H}$ and energy efficiency measures would enable comparing the two more thoroughly using cost-benefit analysis in the future.

While the system cost savings of residential $\mathrm{P} 2 \mathrm{H}$ solutions were found to be larger in more isolated power systems, this was achieved at least partly at the house owners' expense. Strict system cost optimal P2H operation of residential heating systems could result in their excessive use, increasing the 
yearly heating costs of flexible buildings. As house owners are potentially capable of independently minimizing their heating costs, such control schemes are unlikely to gain acceptance without additional incentives to the house owners. Comparatively, energy efficiency improvements yielded significantly more heating cost savings for the house owners than $\mathrm{P} 2 \mathrm{H}$, especially when other retail electricity price components are considered in addition to the power market price. However, the cost savings of residential $\mathrm{P} 2 \mathrm{H}$ were only slightly reduced by the energy efficiency improvements, potentially making it viable to combine the two in the future building stock.

Author Contributions: Conceptualization, T.R. and J.K.; Data Curation, T.R.; Formal Analysis, T.R.; Investigation, T.R.; Methodology, T.R. and J.K.; Software, T.R. and J.K.; Supervision, J.K.; Validation, T.R.; Visualization, T.R.; Writing-Original Draft, T.R. and J.K.; Writing-Review and Editing, T.R. and J.K.

Funding: This project has received funding from the European Union's Horizon 2020 research and innovation programme under Grant No. 646116, as well as from the Academy of Finland under project number 284973.

Acknowledgments: The authors would like to thank Jari Miettinen for providing the wind power forecasts, as well as Terttu Vainio for providing the Finnish building stock forecasts.

Conflicts of Interest: The authors declare no conflict of interest. The funders had no role in the design of the study; in the collection, analyses, or interpretation of data; in the writing of the manuscript, or in the decision to publish the results.

\section{Nomenclature}

DHW Domestic hot water

DSM Demand-side management

LP Linear programming

nZEB Nearly zero-energy building

O\&M Operation and maintenance

Rfb Refurbished

RH Resistive heater

SH Storage heater

SSH Super storage heater

UC Unit commitment

VRE Variable renewable energy

CHP Combined heat and power

ECMWF European Centre of Medium Range Weather Forecasts

GFA Gross floor area

HRU Heat recovery unit

nZEB Nearly zero-energy building

P2H Power-to-heat

$F$ Fuel index

$f$ Model forecast branch index

$n$ Energy network node index

$t$ Model time step index

$u$ Power generator and/or consumer unit index

$\mathbf{F}_{u}$ Set of fuels $F$ used by unit $u$

$\mathbf{N}_{n}$ Set of nodes $n^{\prime}$ connected to node $n$

$\mathbf{N}_{w}$ Set of hydropower reservoir nodes

$\mathbf{U}_{n}$ Set of units $u$ connected to node $n$

$\Delta_{t}$ Length of time step $t$ in hours

$\tau_{n, f, t}^{\text {influx }}$ Energy influx/outflux time series of node $n$ on forecast $f$ and time step $t$

$c_{u, F}^{f u e l \& e m i s s i o n}$ Cost of fuel $F$ for unit $u$ including emission costs

$c_{u}^{O \& M}$ O\&M costs of unit $u$

$c_{u}^{u}$ tartup\&emission
$c_{u}$ Start-up costs of unit $u$ including emission costs

$p_{n, n^{\prime}}^{\text {diffCoeff }}$ Energy diffusion rate parameter between nodes $n$ and $n^{\prime}$

$p_{n}^{\text {energyCapacity }}$ Energy content parameter of node $n$ 
$p_{f, t}^{\text {probability }}$ Probability parameter on forecast $f$ and time step $t$

$p^{\text {reservoirValue }}$ Parameter for appraising the changes in hydropower reservoir levels

$p_{n}^{\text {selfDischargeLoss }}$ Self-discharge rate parameter of node $n$

$p_{n, n^{\prime}}^{\text {transferLoss }}$ Energy transfer loss parameter between nodes $n$ and $n^{\prime}$

$v_{u, F, f, t}^{f u e l \text { se }}$ Fuel $F$ use variable of unit $u$ for forecast $f$ and time step $t$

$v_{n, u, f, t}^{\text {generation }}$ Energy generation/consumption of unit $u$ on node $n$ on forecast $f$ and time step $t$

$v^{\text {objective }}$ Objective variable to be minimized

$v_{n, f, t}^{\text {spill }}$ Energy spill variable of node $n$ on forecast $f$ and time step $t$

$v_{u, f, t}^{\text {startup }}$ Start-up variable of unit $u$ on forecast $f$ and time step $t$

$v_{n, f, t}^{\text {state }}$ State variable of node $n$ on forecast $f$ and time step $t$

$v_{n, n^{\prime}, f, t}^{\text {transfer }}$ Energy transfer variable from node $n$ to node $n^{\prime}$ on forecast $f$ and time step $t$

MEÚR Million euros

$\mathrm{MW}_{F}$ Megawatts of fuel consumption

MWe Megawatts of electric power

$\mathrm{MWh}_{e}$ Megawatt-hours of electricity

$\mathrm{MWh}_{F}$ Megawatt-hours of fuel energy content

\section{Appendix A. Power System Data Description}

\section{Appendix A.1. Generation Capacity and Power Plant Properties}

The distribution of generation capacity within the countries was based on the results of the e-Highway2050 project [34] "Large scale RES" scenario, but most of the country-level generation capacities were scaled to match the results of the European Reference Scenario 2016 [33]. However, as Norway is not an EU member state and is not included in the European Reference Scenario 2016 [33], the e-Highway2050 project results [34] were used as is.

Thermal generation capacities using fossil and biomass fuels were divided into condensing and combined heat and power (CHP) capacities based on the European Reference Scenario 2016 results [33], neglecting the possibility of nuclear CHP generation. Furthermore, enough pure heat generation capacity was added to the system to cover for the required heat demand, and assumed to be distributed identically to the CHP generation capacity.

The technical parameters of the power plants were mostly based on technology catalogs published by the Danish Energy Agency [46,47], but a report by the European Commission's Joint Research Centre was occasionally consulted as well [48]. The variable operational and maintenance costs of power plants, as well as the start-up fuel consumption, were based on more specialized sources $[49,50]$. The power plant stock was further divided into nine efficiency groups based on proprietary databases of the current Northern European power system, in order to better capture the effects of power plant diversity by age and exact generation technology on the marginal generation costs. Due to the proprietary nature of some of the power plant data, the raw power system data cannot be re-shared.

\section{Appendix A.2. Interconnections and Reserve Requirements}

Similar to the generation capacity, the sub-country transmission capacities were based on the e-Highway 2050 project results [34], while the total transmission capacities between countries were scaled to match expected capacities in the Ten-Year Network Development Plan 2016 [35].

The reserve requirements for the Nordic power system were based on current policies outlined the Nordic System Operation Agreement [51], with the exception that the Olkiluoto 3 nuclear power plant was assumed to become the dimensioning fault by 2030. The reserve requirements of the modeled parts of continental Europe were loosely based on European Network of Transmission System Operators for Electricity (ENTSO-E) guidelines [52,53]. 
Appendix A.3. Electrical and Heat Load Time Series

Historical Nordpool electricity demand time series from 2013 were used for Finland, Sweden, Norway, and Estonia, while Ten-Year Network Development Plan 2016 [35] market modeling data is used for countries outside Nordpool. The heat demand time series were based on the Ten-Year Network Development Plan 2016 [35] electricity demand time series as well, although there is no clear indication whether they represent any actual historical year or not. All the demand time series were scaled to match the total yearly electricity and heat demand values in the European Reference Scenario 2016 [33] results, with the exception of Norway.

As Norway is not included in the European Reference Scenario 2016 [33], the total yearly electricity consumption was scaled to match the e-Highway 2050 project results [34] instead. The total yearly heat demand for Norway is based on a report by Institute for Energy Technology [54], and assumed to increase from 2020 to 2030 similarly to electricity demand.

\section{Appendix A.4. Weather, Renewable Generation, and Hydropower}

The ambient temperature, solar radiation, and capacity factor time series of wind and solar power plants in the Nordic countries were based on MERRA-2 datasets [55-57] for the year 2013, while the wind and solar capacity factors for Germany, Poland and the Baltic countries were based on data from renewables.ninja [58,59]. Additionally, ensemble forecasts for the year 2013 by the European Centre of Medium Range Weather Forecasts (ECMWF) were used for generating the ambient temperature and wind power capacity factor forecasts for the stochastic optimization.

Hydropower inflow time series were estimated based on data from the Norwegian Water Resources and Energy Directorate, Svensk Energi, and Finnish Environmental Institute for the year 2012, as data for 2013 was unavailable. The maximum permitted hydropower reservoir levels were based on the NordPool maximum historical reservoir levels of the years 2013-2016, and assumed to increase linearly along with reservoir hydropower capacity in the European Reference Scenario 2016 [33] and e-Highway 2050 project results [34] towards 2030. The initial reservoir levels were based on the historical reservoir levels at the beginning of the year 2012.

The reservoir value parameters used for appraising the water levels in the hydropower reservoirs were based on the yearly average marginal cost of generation for the entire modeled power system. As with the other modeled generation technologies, reservoir hydropower was divided into nine efficiency categories, resulting in varying operation and maintenance costs. The reservoir value for each wind and solar multiplied scenario was set in a way that half of the reservoir hydropower capacity had marginal generation costs above the yearly average marginal cost of generation, and are presented in Table A1.

Table A1. Assumed reservoir values for the different solar and wind multiplied scenarios in both case studies.

\begin{tabular}{|c|c|c|c|c|c|}
\hline \multirow[b]{2}{*}{$\left(\mathrm{EUR} / \mathrm{MWh}_{e}\right)$} & \multicolumn{5}{|c|}{ Wind \& Solar Multiplier } \\
\hline & $1 \times$ & $2 \times$ & $3 \times$ & $4 \times$ & $5 \times$ \\
\hline \multirow[t]{2}{*}{ Finland } & 43.25 & 28.39 & 20.01 & 14.68 & 11.08 \\
\hline & \multicolumn{5}{|c|}{ Wind \& Solar Multiplier } \\
\hline$\left(\mathrm{EUR} / \mathrm{MWh}_{e}\right)$ & $0.5 \times$ & $1 \times$ & $1.5 \times$ & $2 \times$ & $2.5 \times$ \\
\hline Nordic & 50.52 & 41.88 & 29.29 & 10.98 & 6.95 \\
\hline
\end{tabular}

Appendix A.5. Fuel and Carbon Prices

The future fossil fuel prices were based on a report by the UK Department for Business, Energy and Industrial Strategy [60], with lignite assumed to be $11 \%$ cheaper than coal [48]. The price of nuclear fuel was calculated assuming total fuel cycle costs of $9.33 \mathrm{USD} / \mathrm{MWh}_{e}[61]$ and an assumed 33\% conversion efficiency of a second generation light water reactor [48]. Biomass prices were based on a 
report by Pöyry Management Consulting Oy [62]. All the fuel prices were converted to EUR/MWh using energy conversion factors from the IEA Unit Converter [63] and the 10 year average currency exchange rates between 27 November 2007-27 November 2017 from the European Central Bank [64]. The assumed fuel prices are presented in Table A2.

Table A2. Fuel price assumptions.

\begin{tabular}{cc}
\hline Fuel & Price (EUR/MWh \\
\hline Biomass (fuels) & 24.00 \\
Biomass (waste) & 15.00 \\
Coal & 7.69 \\
Gas & 25.69 \\
Lignite & 6.85 \\
Nuclear & 2.41 \\
Oil & 39.03 \\
\hline
\end{tabular}

The used carbon price of $33.50 \mathrm{EUR} / \mathrm{tCO}_{2}$ were based on the European Reference Scenario 2016 [33], and the $\mathrm{CO}_{2}$ content of the fuels was based on IPCC guidelines [65].

\section{Appendix B. Building Stock Data Description}

\section{Appendix B.1. Finnish Detached Housing Stock}

The future state of the residential housing stock was based on pre-existing modeling results about the future development of the residential building stock [36,37], and the structural data for the different building age categories was based on national building industry knowledge services archives [66]. Unfortunately, these data sources are proprietary, and the raw input data for the building stock modeling and aggregation cannot be re-shared. However, some key properties of the aggregated building stock are presented later in Tables A3-A8.

The building envelope structures were assumed to be independent of the heating systems for simplicity, even though electrically heated houses have typically been slightly better insulated due to their higher cost of energy. The structural layers of future detached houses were assumed to remain similar to contemporary ones, except that the amount of insulation was increased to meet the future energy efficiency requirements of nearly zero-energy buildings (nZEB) $[67,68]$. The ventilation properties were based on empirical studies of the existing housing stock $[69,70]$, and the properties of the structural materials are based on a literature survey [71]. The detached houses were assumed not to have undergone any refurbishments in the baseline scenario, as there are no reliable data sources to reliably estimate the amount and level of refurbishments.

\section{Appendix B.2. Energy Refurbishments}

The minimum refurbishments required by the Ministry of the Environment [29] have been implemented in the data files. The insulation thickness in the external walls and ceilings were increased in all the refurbished houses until 2020 to match the minimum required U-values of the structures [29]. The floor structures were only refurbished in the age categories before the 1960s by changing the insulation material into modern ones, as later slab-on-grade floors are extremely costly to refurbish properly [31,32]. These changes correspond roughly to the suggested external adding of insulation suggested in the various sources to avoid moisture related issues that adding insulation to the interior could cause [32]. Fenestration in all the refurbished categories was set to match the 2010-2020 parameters, as these are the oldest structures that meet the requirements set in the degree. Ventilation in the buildings before the 1980s was not refurbished, as these buildings are typically naturally ventilated and the air-tightness of the envelope is rather poor. Installing heat recovery units (HRUs) would thus require investing into a whole new mechanical ventilation system, as well as improving the air-tightness of the envelope [30,31]. From the 1980s onwards, the houses were installed with HRUs with a minimum efficiency of $45 \%$, and the ventilation and infiltration rates were set to match the 2010-2020 standard values. 
The nZEB refurbishments were also implemented by increasing the insulation thickness of all existing structures to match proposed U-values for Nordic passive houses [72], this time even with the slab-on-grade floors. Unlike the above-mentioned refurbishments, the nZEB refurbishments would often be prohibitively expensive to realize, and serve as an extreme comparison. Similarly, the air-tightness and ventilation HRUs were improved/installed to match the proposed requirements.

\section{Appendix B.3. Detached Housing Stock Aggregation}

The electrically heated detached housing stock was represented using two archetype houses, one for the Southern Finland and one for the Northern Finland. The properties of the archetype buildings were aggregated from municipality-level building stock data, illustrated in Figure A1, and detailed structural data of typical structures used in construction during different periods. Key properties regarding the aggregation of the detached housing stock are presented in Tables A3 and A4 for the expected housing stock, in Tables A5 and A6, for the refurbished housing stock, and in Tables A7 and A8 for the nZEB refurbished housing stock.

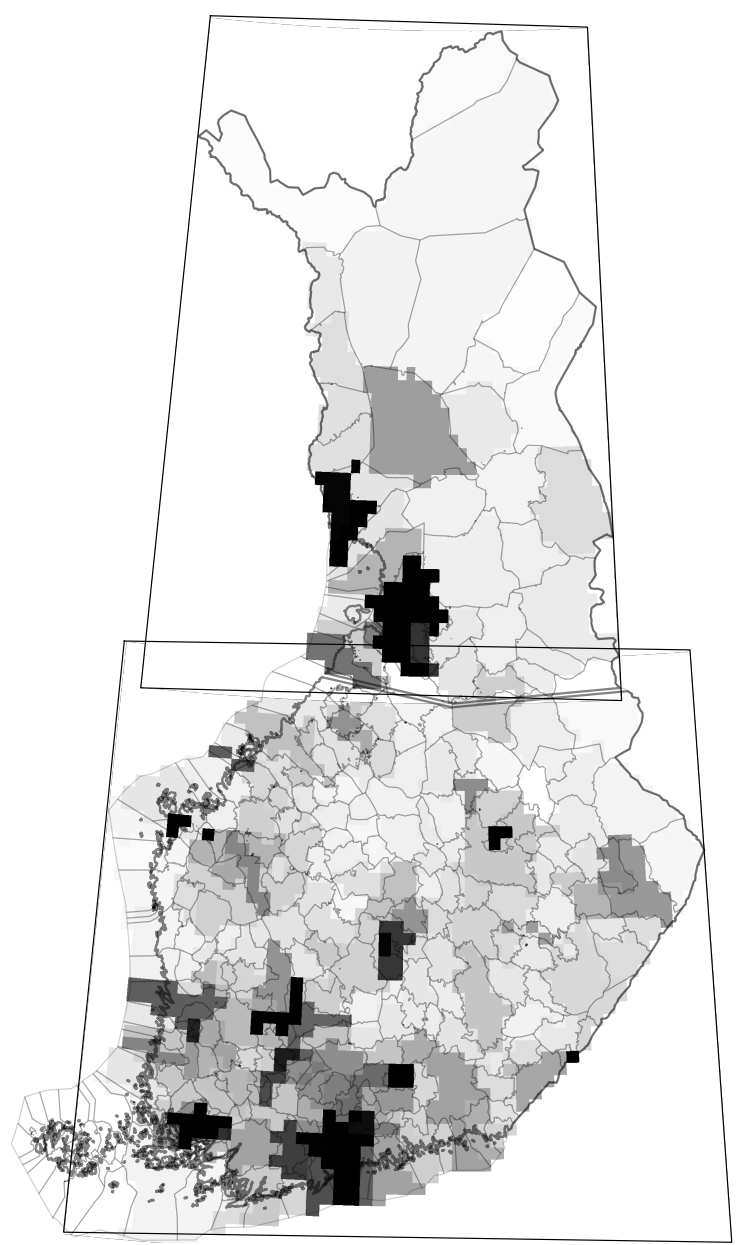

Figure A1. Illustration of the municipality-level building stock data, as well as the derived gross floor area density rasters used for the weighed averaging of the weather data for the archetype houses. Darker areas indicate higher gross floor area density, with black representing the maximum density value of the corresponding raster. The rasters for Northern and Southern Finland being highlighted using the bounding boxes, and are not directly comparable, as the maximum gross floor area density in Northern Finland is significantly lower than in Southern Finland. The borders of the power system node regions are shown in dark gray, and the borders of the municipality level building stock data used for generating the rasters are shown in light gray. 
Table A3. Electrically heated detached housing stock aggregation for the expected 2030 housing stock for the 74FI Northern Finland archetype.

\begin{tabular}{|c|c|c|c|c|c|}
\hline Time Period & Number & Average Gross Floor Area $\left(\mathrm{m}^{2}\right)$ & Total Effective Heat Capacity $\left(\mathrm{Wh} / \mathrm{m}^{2} \mathrm{~K}\right)$ & Total Heat Loss Coefficient $\left(\mathrm{W} / \mathrm{m}^{2} \mathrm{~K}\right)$ & Time Constant (h) \\
\hline-1940 & 658 & 98.26 & 67.46 & 1.98 & 34.04 \\
\hline 1940-1960 & 5172 & 102.97 & 32.38 & 1.93 & 16.78 \\
\hline 1960-1980 & 8406 & 126.24 & 52.66 & 1.83 & 28.81 \\
\hline 1980-2000 & 23,549 & 150.56 & 53.75 & 1.57 & 34.25 \\
\hline 2000-2010 & 7101 & 167.83 & 49.92 & 1.15 & 43.50 \\
\hline $2010-2020$ & 2887 & 159.77 & 55.66 & 0.94 & 59.48 \\
\hline $2020-2030$ & 2791 & 159.69 & 55.58 & 0.79 & 70.70 \\
\hline Archetype & 50,563 & 144.43 & 45.75 & 1.45 & 31.57 \\
\hline
\end{tabular}

Table A4. Electrically heated detached housing stock aggregation for the expected 2030 housing stock for the 75FI Southern Finland archetype.

\begin{tabular}{|c|c|c|c|c|c|}
\hline Time Period & Number & Average Gross Floor Area $\left(\mathrm{m}^{2}\right)$ & Total Effective Heat Capacity $\left(\mathrm{Wh} / \mathrm{m}^{2} \mathrm{~K}\right)$ & Total Heat Loss Coefficient $\left(\mathrm{W} / \mathrm{m}^{2} \mathrm{~K}\right)$ & Time Constant (h) \\
\hline-1940 & 13,353 & 111.90 & 65.08 & 1.91 & 34.03 \\
\hline $1940-1960$ & 45,789 & 109.60 & 31.75 & 1.90 & 16.74 \\
\hline 1960-1980 & 49,327 & 138.89 & 51.97 & 1.80 & 28.95 \\
\hline 1980-2000 & 141,192 & 164.54 & 53.32 & 1.55 & 34.46 \\
\hline 2000-2010 & 59,870 & 177.18 & 49.64 & 1.13 & 43.76 \\
\hline $2010-2020$ & 23,304 & 173.84 & 55.10 & 0.92 & 60.04 \\
\hline 2020-2030 & 22,881 & 173.93 & 55.01 & 0.77 & 71.54 \\
\hline Archetype & 355,717 & 155.28 & 45.81 & 1.41 & 32.50 \\
\hline
\end{tabular}

Table A5. Electrically heated detached housing stock aggregation for the refurbished 2030 housing stock for the 74FI Northern Finland refurbished archetype.

\begin{tabular}{|c|c|c|c|c|c|}
\hline Time Period & Number & Average Gross Floor Area $\left(\mathrm{m}^{2}\right)$ & Total Effective Heat Capacity $\left(\mathrm{Wh} / \mathrm{m}^{2} \mathrm{~K}\right)$ & Total Heat Loss Coefficient $\left(\mathrm{W} / \mathrm{m}^{2} \mathrm{~K}\right)$ & Time Constant (h) \\
\hline-1940 & 658 & 98.26 & 76.00 & 1.20 & 63.15 \\
\hline 1940-1960 & 5172 & 102.97 & 43.60 & 1.22 & 35.60 \\
\hline 1960-1980 & 8406 & 126.24 & 52.66 & 1.35 & 39.07 \\
\hline $1980-2000$ & 23,549 & 150.56 & 53.75 & 1.11 & 48.31 \\
\hline 2000-2010 & 7101 & 167.83 & 63.92 & 1.04 & 61.54 \\
\hline 2010-2020 & 2887 & 159.77 & 55.66 & 0.93 & 59.77 \\
\hline 2020-2030 & 2791 & 159.69 & 47.54 & 0.75 & 63.71 \\
\hline Archetype & 50,563 & 144.43 & 46.62 & 1.06 & 43.79 \\
\hline
\end{tabular}


Table A6. Electrically heated detached housing stock aggregation for the refurbished 2030 housing stock for the 75FI Southern Finland refurbished archetype.

\begin{tabular}{|c|c|c|c|c|c|}
\hline Time Period & Number & Average Gross Floor Area $\left(\mathrm{m}^{2}\right)$ & Total Effective Heat Capacity $\left(\mathrm{Wh} / \mathrm{m}^{2} \mathrm{~K}\right)$ & Total Heat Loss Coefficient $\left(\mathrm{W} / \mathrm{m}^{2} \mathrm{~K}\right)$ & Time Constant (h) \\
\hline-1940 & 13,353 & 111.90 & 72.35 & 1.17 & 61.99 \\
\hline 1940-1960 & 45,789 & 109.60 & 42.59 & 1.21 & 35.28 \\
\hline 1960-1980 & 49,327 & 138.89 & 51.97 & 1.33 & 39.18 \\
\hline 1980-2000 & 141,192 & 164.54 & 53.32 & 1.09 & 48.71 \\
\hline 2000-2010 & 59,870 & 177.18 & 63.67 & 1.03 & 61.91 \\
\hline 2010-2020 & 23,304 & 173.84 & 55.10 & 0.91 & 60.34 \\
\hline $2020-2030$ & 22,881 & 173.93 & 46.94 & 0.73 & 64.38 \\
\hline Archetype & 355,717 & 155.28 & 46.95 & 1.04 & 45.17 \\
\hline
\end{tabular}

Table A7. Electrically heated detached housing stock aggregation for the excessively refurbished 2030 housing stock for the 74FI Northern Finland nZEB archetype.

\begin{tabular}{|c|c|c|c|c|c|}
\hline Time Period & Number & Average Gross Floor Area $\left(\mathrm{m}^{2}\right)$ & Total Effective Heat Capacity $\left(\mathrm{Wh} / \mathrm{m}^{2} \mathrm{~K}\right)$ & Total Heat Loss Coefficient $\left(\mathrm{W} / \mathrm{m}^{2} \mathrm{~K}\right)$ & Time Constant (h) \\
\hline-1940 & 658 & 98.26 & 76.00 & 0.86 & 88.73 \\
\hline 1940-1960 & 5172 & 102.97 & 43.60 & 0.89 & 49.15 \\
\hline 1960-1980 & 8406 & 126.24 & 52.66 & 0.87 & 60.55 \\
\hline 1980-2000 & 23,549 & 150.56 & 53.75 & 0.84 & 64.01 \\
\hline 2000-2010 & 7101 & 167.83 & 63.92 & 0.85 & 75.07 \\
\hline $2010-2020$ & 2887 & 159.77 & 55.66 & 0.80 & 69.78 \\
\hline 2020-2030 & 2791 & 159.69 & 47.54 & 0.72 & 65.79 \\
\hline Archetype & 50,563 & 144.43 & 46.62 & 0.82 & 57.17 \\
\hline
\end{tabular}

Table A8. Electrically heated detached housing stock aggregation for the excessively refurbished 2030 housing stock for the 75FI Southern Finland nZEB archetype.

\begin{tabular}{|c|c|c|c|c|c|}
\hline Time Period & Number & Average Gross Floor Area $\left(\mathrm{m}^{2}\right)$ & Total Effective Heat Capacity $\left(\mathrm{Wh} / \mathrm{m}^{2} \mathrm{~K}\right)$ & Total Heat Loss Coefficient $\left(\mathrm{W} / \mathrm{m}^{2} \mathrm{~K}\right)$ & Time Constant (h) \\
\hline-1940 & 13353 & 111.90 & 72.35 & 0.82 & 87.99 \\
\hline $1940-1960$ & 45,789 & 109.60 & 42.59 & 0.87 & 48.92 \\
\hline $1960-1980$ & 49,327 & 138.89 & 51.97 & 0.85 & 61.22 \\
\hline $1980-2000$ & 141,192 & 164.54 & 53.32 & 0.82 & 64.84 \\
\hline $2000-2010$ & 59,870 & 177.18 & 63.67 & 0.84 & 75.66 \\
\hline $2010-2020$ & 23,304 & 173.84 & 55.10 & 0.78 & 70.60 \\
\hline $2020-2030$ & 22,881 & 173.93 & 46.94 & 0.71 & 66.52 \\
\hline Archetype & 355,717 & 155.28 & 46.95 & 0.80 & 58.82 \\
\hline
\end{tabular}


The weather data for the archetype houses was aggregated using the same municipality-level building stock data, by calculating the gross floor area (GFA) density $\left(\mathrm{m}^{2} / \mathrm{km}^{2}\right)$ of the archetype houses for each municipality. This GFA density map was then converted into $50 \times 50$ pixel rasters depicting the geographical distribution of the archetype houses, illustrated in Figure A1, and used to calculate the weighed average ambient temperature and solar radiation time series from the MERRA-2 [55-57] data. The ambient temperature time series were used for calculating the effective ground temperature time series according to [73], and the solar radiation time series were used for calculating the solar gains of the archetype houses according to [40].

\section{Appendix C. Building Thermal Model Details}

The thermal dynamics of the archetype buildings were depicted using a simple lumped capacitance model. The effective thermal masses of the temperature nodes were calculated based on EN ISO 13790 [40], assuming that the heat capacity of the structural layers outside the insulation have a negligible impact on the effective thermal mass. The heat transfer coefficients between the temperature nodes were calculated according to EN ISO 13789 [41], EN ISO 6946 [42] and national guidelines [43]. However, the ground coupled heat losses of the slab-on-ground floor structures were calculated using a simple hourly method by Kissock et al. [73], as opposed to the monthly methods proposed in the standards. The ventilation and infiltration were described simply via average air exchange rate parameters mainly based on national empirical studies [69,70], and heat recovery units were simply described with an average heat recovery efficiency parameter.

The internal heat gains from inhabitants, appliances and lights, as well as solar gains were calculated according to EN ISO 13790, while neglecting the radiative heat losses and solar gains through the opaque parts of the building envelope for simplicity. However, the profiles of the internal gains and DHW demand were based on design profiles presented in national guidelines [44].

The followings sections describe the various parameters and assumptions required for the modeling of the heating systems in typical Finnish detached houses. Direct electrical heating systems were sized for $25 \mathrm{~W} / \mathrm{m}^{3}$ and SH systems for $37.5 \mathrm{~W} / \mathrm{m}^{3}$ based on a typical construction industry rule-of-thumb in Finland.

\section{Appendix C.1. Domestic Hot Water Tank}

Typical residential DHW storage tanks are assumed to have power between $1.5-3 \mathrm{~kW}$ and a volume of around 200-300 L [74,75]. Typically, the temperature of the water in the DHW storage tank is maintained between $55-80{ }^{\circ} \mathrm{C}$ [76], but, due to the occasionally required temperature of $60^{\circ} \mathrm{C}$ for ensuring legionella decontamination, the modelled range is reduced to $60-80{ }^{\circ} \mathrm{C}$. The heat loss coefficients were based on national guidelines [44]:

\section{Parameters}

- Heating power: $3 \mathrm{~kW}$,

- Heat capacity: $347.69 \mathrm{Wh} / \mathrm{K}$,

- Heat loss coefficient: $1.73 \mathrm{~W} / \mathrm{K}$,

- Permitted temperature range: $60-80{ }^{\circ} \mathrm{C}$.

\section{Appendix C.2. Direct Resistive Heating}

Simply converts electricity from the power system into heat to the interior air node with $100 \%$ efficiency. Sizing based on a common Finnish construction industry rule-of-thumb for sizing electric heating systems $25 \mathrm{~W} / \mathrm{m}^{3}[74,75]$ assuming a $2.5 \mathrm{~m}$ room height.

\section{Parameters}

- Heating power GFA scaling coefficient: $62.5 \mathrm{~W} / \mathrm{m}^{2}$ 


\section{Appendix C.3. Storage Heating}

Storage heaters are extremely rare in Finland, and there are no clear guidelines on how such systems should be sized. Thus, we assumed that such systems would be sized similarly to other forms of electric heating with storage, e.g., electric floor heating. For such systems, the heating power is often oversized by around $50 \%$ compared to direct electric heating systems [74,75], in order to compensate for the slower response to changes in heat demand. The parameters for the storage heater system were based on the technical parameters of existing smart storage heaters [77], and the aforementioned electric heating sizing rule-of-thumb with the above-mentioned oversizing. For the modeled "super" storage heater, the heat capacity was simply tripled, without changing the other parameters:

\section{Parameters}

- Heating power GFA sizing coefficient: $93.75 \mathrm{~W} / \mathrm{m}^{2}$,

- Heat capacity GFA sizing coefficient: $0.90 \mathrm{Wh} / \mathrm{m}^{2} \mathrm{~K}$ (2.70 for the super storage heater),

- Heat loss coefficient per GFA: $0.05 \mathrm{~W} / \mathrm{m}^{2} \mathrm{~K}$,

- Permitted temperature range: $30-580^{\circ} \mathrm{C}$.

\section{References}

1. International Energy Agency (IEA). Key World Energy Statistics 2017; Technical Report; IEA: Paris, France, 2017.

2. International Renewable Energy Agency (IRENA). Renewable Power Generation Costs in 2017; Technical Report; IRENA: Abu Dhabi, UAE, 2018.

3. Lund, P.D.; Lindgren, J.; Mikkola, J.; Salpakari, J. Review of energy system flexibility measures to enable high levels of variable renewable electricity. Renew. Sustain. Energy Rev. 2015, 45, 785-807. [CrossRef]

4. Torriti, J.; Hassan, M.G.; Leach, M. Demand response experience in Europe: Policies, programmes and implementation. Energy 2010, 35, 1575-1583. [CrossRef]

5. Bloess, A.; Schill, W.P.; Zerrahn, A. Power-to-heat for renewable energy integration: A review of technologies, modeling approaches, and flexibility potentials. Appl. Energy 2018, 212, 1611-1626. [CrossRef]

6. Hu, J.; Morais, H.; Sousa, T.; Lind, M. Electric vehicle fleet management in smart grids: A review of services, optimization and control aspects. Renew. Sustain. Energy Rev. 2016, 56, 1207-1226. [CrossRef]

7. European Commission. Roadmap 2050; Technical Report; European Commission: Luxembourg, 2012. [CrossRef]

8. Gielen, D.; Gorini, N.W.; Rodrigo, L.; Gutierrez, L.; Prakash, G.; Durrant, P.; Janeiro, L.; Winter, J.; Casals, X.; Parajuli, B.; et al. Global Energy Transformation: A Roadmap to 2050; Technical Report; International Renewable Energy Agency (IRENA): Abu Dhabi, UAE, 2018.

9. Tronchin, L.; Manfren, M.; Nastasi, B. Energy efficiency, demand side management and energy storage technologies-A critical analysis of possible paths of integration in the built environment. Renew. Sustain. Energy Rev. 2018, 95, 341-353. [CrossRef]

10. Cooper, S.J;; Hammond, G.P.; McManus, M.C.; Pudjianto, D. Detailed simulation of electrical demands due to nationwide adoption of heat pumps, taking account of renewable generation and mitigation. IET Renew. Power Gener. 2016, 10, 380-387. [CrossRef]

11. Patteeuw, D.; Bruninx, K.; Arteconi, A.; Delarue, E.; D’haeseleer, W.; Helsen, L. Integrated modeling of active demand response with electric heating systems coupled to thermal energy storage systems. Appl. Energy 2015, 151, 306-319. [CrossRef]

12. Papaefthymiou, G.; Hasche, B.; Nabe, C. Potential of Heat Pumps for Demand Side Management and Wind Power Integration in the German Electricity Market. IEEE Trans. Sustain. Energy 2012, 3, 636-642. [CrossRef]

13. Hedegaard, K.; Mathiesen, B.V.; Lund, H.; Heiselberg, P. Wind power integration using individual heat pumps-Analysis of different heat storage options. Energy 2012, 47, 284-293. [CrossRef]

14. Mathieu, J.L.; Dyson, M.E.; Callaway, D.S. Resource and revenue potential of California residential load participation in ancillary services. Energy Policy 2015, 80, 76-87. [CrossRef]

15. Teng, F.; Aunedi, M.; Strbac, G. Benefits of flexibility from smart electrified transportation and heating in the future UK electricity system. Appl. Energy 2016, 167, 420-431. [CrossRef] 
16. Olkkonen, V.; Rinne, S.; Hast, A.; Syri, S. Benefits of DSM measures in the future Finnish energy system. Energy 2017, 137, 729-738. [CrossRef]

17. Good, N.; Karangelos, E.; Navarro-Espinosa, A.; Mancarella, P. Optimization Under Uncertainty of Thermal Storage-Based Flexible Demand Response With Quantification of Residential Users' Discomfort. IEEE Trans. Smart Grid 2015, 6, 2333-2342. [CrossRef]

18. Nyholm, E.; Puranik, S.; Mata, E.; Odenberger, M.; Johnsson, F. Demand response potential of electrical space heating in Swedish single-family dwellings. Build. Environ. 2016, 96, 270-282. [CrossRef]

19. Alahäivälä, A.; Corbishley, J.; Ekström, J.; Jokisalo, J.; Lehtonen, M. A control framework for the utilization of heating load flexibility in a day-ahead market. Electr. Power Syst. Res. 2017, 145, 44-54. [CrossRef]

20. Arteconi, A.; Patteeuw, D.; Bruninx, K.; Delarue, E.; D’haeseleer, W.; Helsen, L. Active demand response with electric heating systems: Impact of market penetration. Appl. Energy 2016, 177, 636-648. [CrossRef]

21. Hedegaard, K.; Balyk, O. Energy system investment model incorporating heat pumps with thermal storage in buildings and buffer tanks. Energy 2013, 63, 356-365. [CrossRef]

22. Patteeuw, D.; Reynders, G.; Bruninx, K.; Protopapadaki, C.; Delarue, E.; D'haeseleer, W.; Saelens, D.; Helsen, L. $\mathrm{CO}_{2}$-abatement cost of residential heat pumps with active demand response: Demand- and supply-side effect. Appl. Energy 2015, 156, 490-501. [CrossRef]

23. Patteeuw, D.; Henze, G.P.; Helsen, L. Comparison of load shifting incentives for low-energy buildings with heat pumps to attain grid flexibility benefits. Appl. Energy 2016, 167, 80-92. [CrossRef]

24. Statistics Finland. Official Statistics of Finland: Energy Consumption in Households; Statistics Finland: Helsinki, Finland, 2017.

25. Alahäivälä, A.; Ekström, J.; Jokisalo, J.; Lehtonen, M. A framework for the assessment of electric heating load flexibility contribution to mitigate severe wind power ramp effects. Electr. Power Syst. Res. 2017, 142, 268-278. [CrossRef]

26. Kilkki, O.; Alahaivala, A.; Seilonen, I. Optimized Control of Price-Based Demand Response with Electric Storage Space Heating. IEEE Trans. Ind. Inform. 2015, 11, 281-288. [CrossRef]

27. Kilkki, O.; Seilonen, I.; Zenger, K.; Vyatkin, V. Optimizing residential heating and energy storage flexibility for frequency reserves. Int. J. Electr. Power Energy Syst. 2018, 100, 540-549. [CrossRef]

28. Kiviluoma, J.; Rinne, E.; Rasku, T.; Helistö, N. Backbone-An Adaptable Energy System Model—GitLab Repository. 2018. Available online: https:/ / gitlab.vtt.fi/backbone/backbone (accessed on 27 April 2018).

29. Kiuru, K.; Kauppinen, J. Ministry of the Environment degree on improving the energy performance of buildings undergoing renovation or alternation. Ministry of the Environment: Helsinki, Finland, 2013.

30. Holopainen, R.; Hekkanen, M.; Norvasuo, M. Suomalaisten Rakennusten Energiakorjausmenetelmät ja Säästöpotentiaalit (Energy Renovation Technologies and Saving Potentials of Finnish Buildings); Technical Report; VTT Technical Research Centre of Finland: Espoo, Finland, 2007. (In Finnish)

31. Heljo, J.; Vihola, J. Energiansäästömahdollisuudet Rakennuskannan Korjaustoiminnassa (Energy Savings Potential in Renovating the Building Stock); Technical Report; Tampere University of Technology, Department of Civil Engineering: Tampere, Finland, 2012. (In Finnish)

32. Nieminen, J.; Virta, J. Rakennusten Lisälämmöneristäminen (Additional Insulation of Buildings); Technical Report; Kiinteistöalan Kustannus Oy: Helsinki, Finland, 2016. (In Finnish)

33. Capros, P.; De Vita, A.; Tasios, N.; Siskos, P.; Kannavou, M.; Petropoulos, A.; Evangelopoulou, S.; Zampara, M.; Papadopoulos, D.; Nakos, C.; et al. EU Reference Scenario 2016: Energy, Transport and GHG Emissions Trends to 2050; Technical Report; National Technical University of Athens: Athens, Greece, 2016. [CrossRef]

34. e-Highway 2050 consortium. e-Highway 2050 Project Website. 2013. Available online: http://www.ehighway2050.eu/e-highway2050 / (accessed on 29 June 2017).

35. European Network of Transmission System Operators for Electricity (ENTSO-E). Ten Year Network Development Plan 2016; ENTSO-E: Brussels, Belgium, 2016.

36. Vainio, T.; Belloni, K.; Jaakkonen, L. Asuntotuotanto 2030-Asuntotuotantotarpeeseen Vaikuttavia Tekijöitä (Dwelling Production 2030 - Factors Affecting the Amount of New Housing Construction); Technical Report; VTT Technical Research Centre of Finland: Espoo, Finland, 2012. (In Finnish)

37. Vainio, T. Asuntotuotantotarve 2015-2040 (Demand for Dwelling Production 2015-2040); Technical Report; VTT Technical Research Centre of Finland Ltd.: Espoo, Finland, 2016. (In Finnish) 
38. Ministry of the Environment. D3 Rakennusten Energiatehokkuus-Määräykset Ja Ohjeet 2012 (D3 Energy Efficiency of Buildings-Regulations and Guidelines 2012); Technical Report; Ministry of the Environment: Helsinki, Finland, 2012. (In Finnish)

39. O’Dwyer, C.; Anwar, M.; Dillon, J.; Bakhtvar, M.; Buttitta, G.; Cabrera, C.A.; Baltputnis, K.; Broka, Z.; Kozadajevs, J.; Sauhats, A.; et al. H2020 RealValue D3.6 Cost Benefit Analysis of SETS and Alternative Local Small-Scale Storage Options; Technical Report; University College Dublin: Dublin, Ireland, 2018.

40. European Committee for Standardization (CEN). Energy Performance of Buildings_Calculation of Energy Use For Space Heating and Cooling (ISO 13790: 2008); Technical Report; European Committee for Standardization (CEN): Brussels, Belgium, 2008.

41. International Organization for Standardization (ISO). Thermal Performance of Buildings_-Transmission and Ventilation Heat Transfer Coefficients_Calculation Method (ISO 13789:2007); Technical Report; International Organization for Standardization (ISO): Geneva, Switzerland, 2007.

42. European Committee for Standardization (CEN). Building Components and Building Elements-Thermal Resistance And Thermal Transmittance-Calculation Method (ISO 6946:2007); Technical Report; European Committee for Standardization (CEN): Brussels, Belgium, 2007.

43. Ministry of the Environment. Rakennusten Energiankulutuksen Ja Lämmitystehontarpeen Laskenta-Ohjeet 2012 (Calculating the Energy Consumption and Heating Demand of Buildings-Guidelines 2012); Technical Report; Ministry of the Environment: Helsinki, Finland, 2013. (In Finnish)

44. Shemeikka, J.; Laitinen, A.; Klobut, K.; Saari, M.; Kukkonen, P.; Vesanen, T. Lämmitysjärjestelmät Ja Lämmin Käyttövesi-Laskentaopas (Heating Systems and Domestic Hot Water-Calculation Guide); Technical Report; Ministry of the Environment: Helsinki, Finland, 2011. (In Finnish)

45. EQUA Simulation AB; Aalto University. IDA Early Stage Building Optimization (ESBO), Version 1.13. Available online: http:/ / www.equaonline.com/esbo/download.html (accessed on 2 May 2017).

46. Danish Energy Agency. Technology Data for Energy Plants; Technical Report; Danish Energy Agency: Copenhagen, Denmark, 2012.

47. Danish Energy Agency. Technology Data for Energy Plants-August 2016; Technical Report August; Danish Energy Agency: Copenhagen, Denmark, 2016.

48. Carlsson, J.; Fortes, M.D.M.P.; Marco, G.D.; Giuntoli, J.; Jakubcionis, M.; Jäger-Waldau, A.; Lacal-Arantegui, R.; Lazarou, S.; Magagna, D.; Moles, C.; et al. ETRI 2014—Energy Technology Reference Indicator Projections for 2010-2050; Technical Report; Joint Reseach Centre: Brussels, Belgium, 2014. [CrossRef]

49. Kumar, N.; Besuner, P.; Lefton, S.; Agan, D.; Hilleman, D. Power Plant Cycling Costs; Technical Report April; National Renewable Energy Laboratory: Golden, CO, USA, 2012. [CrossRef]

50. Schröder, A.; Friedrich, K.; Meiss, J.; Mendelevitch, R.; von Hirschhausen, C. Current and Prospective Costs of Electricity Generation until 2050 2013; Technical Report; DIW Berlin: Berlin, Germany, 2013.

51. European Network of Transmission System Operators for Electricity (ENTSO-E). AGREEMENT (Translation) Regarding Operation of the Interconnected Nordic Power System (System Operation Agreement); Technical Report 13; ENTSO-E: Brussels, Belgium, 2006.

52. European Network of Transmission System Operators for Electricity (ENTSO-E). P1—Policy 1: Load-Frequency Control and Performance. In Continental Europe Operation Handbook; ENTSO-E: Brussels, Belgium, 2009.

53. European Network of Transmission System Operators for Electricity (ENTSO-E). A1-Appendix 1: Load-Frequency Control and Performance. In Continental Europe Operation Handbook; ENTSO-E: Brussels, Belgium, 2004.

54. Rosenberg, E.; Espegren, K.A. Future Energy Demand-A Norwegian Overview; Technical Report; Institute for Energy Technology: Kjeller, Norway, 2013.

55. Global Modeling and Assimilation Office (GMAO). MERRA-2 tavg1_2d_flx_NX: 2d, 1-Hourly, Time-Averaged, Single-Level, Assimilation, Surface Flux Diagnostics V5.12.4. Available online: https: / / disc.gsfc.nasa.gov / datasets /M2T1NXFLX_V5.12.4/summary?keywords=\%22MERRA-2\%22 (accessed on 25 September 2017). [CrossRef]

56. Global Modeling and Assimilation Office (GMAO). MERRA-2 tavg1_2d_lnd_Nx: 2d,1-Hourly, Time-Averaged, Single-Level, Assimilation, Land Surface Diagnostics V5.12.4. Available online: https:/ / disc.gsfc.nasa.gov/datasets/M2T1NXLND_V5.12.4/summary?keywords=\%22M (accessed on 25 September 2017). [CrossRef] 
57. Global Modeling and Assimilation Office (GMAO). MERRA-2 tavg1_2d_rad_Nx: 2d,1-Hourly, Time-Averaged, Single-Level, Assimilation, Radiation Diagnostics V5.12.4. Available online: https:// disc.gsfc.nasa.gov/datasets /M2T1NXRAD_V5.12.4/summary?keywords=\%22MERRA-2\%22 (accessed on 25 September 2017). [CrossRef]

58. Pfenninger, S.; Staffell, I. Long-term patterns of European PV output using 30 years of validated hourly reanalysis and satellite data. Energy 2016, 114, 1251-1265. [CrossRef]

59. Staffell, I.; Pfenninger, S. Using bias-corrected reanalysis to simulate current and future wind power output. Energy 2016, 114, 1224-1239. [CrossRef]

60. Department for Business Energy \& Industrial Strategy. Beis 2016 Fossil Fuel Price Assumptions; Technical Report November; Department for Business Energy \& Industrial Strategy: London, UK, 2016.

61. Wittenstein, M.; Rothwell, G.; D’haeseleer, W.; Matsuo, Y.; Varro, L.; Frankl, P.; Baritaud, M.; Keppler, J.H.; Yu, C.; Deffrennes, M.; et al. Projected Costs of Generating Electricity, 2015th ed.; Technical Report; Internaltional Energy Agency (IEA), Nuclear Energy Agency (NEA), Organisation for Economic Co-operation and Development (OECD): Paris, France, 2015.

62. Pöyry Management Consulting Oy. Suomen Sähkötehon Riittävyys Ja Kapasiteettirakenteen Kehitys Vuoteen 2030 (Capacity Adequacy and the Future Development of Generation Capacity Until 2030 in Finland); Technical Report; Pöyry Management Consulting Oy: Vantaa, Finland, 2015.

63. International Energy Agency (IEA). IEA Unit Converter; IEA: Paris, France, 2018.

64. European Central Bank. Euro Foreign Exchange Reference Rates. Available online: https://www.ecb.europa. eu/stats/policy_and_exchange_rates/euro_reference_exchange_rates/html/index.en.html (accessed on 27 November 2017).

65. Gómez, D.R.; Watterson, J.D.; Americanohia, B.B.; Ha, C.; Marland, G.; Matsika, E.; Namayanga, L.N.; Osman-Elasha, B.; Saka, J.D.K.; Treanton, K. Stationary Combustion. In 2006 IPCC Guidelines for National Greenhouse Gas Inventories; Eggleston, S., Buendia, L., Miwa, K., Ngara, T., Tanabe, K., Eds.; Institute for Global Environmental Strategies (IGES): Hayama, Japan, 2006; Chapter 2, p. 47.

66. Building Information Foundation RTS sr. RT-Net Archive. Available online: https:/ / www.rakennustieto.fi/ index/tuotteet/rt.html (accessed on 21 September 2016) (In Finnish)

67. European Commission. Directive 2010/31/EU of the European Parliament and of the Council of 19 May 2010 on the Energy Performance of Buildings; European Commission: Brussels, Belgium, 2010.

68. Ministry of the Environment. 1010/2017 Decree of the Ministry of the Environment on the Energy Performance of New Buildings; Ministry of the Environment: Helsinki, Finland, 2017.

69. Vinha, J.; Korpi, M.; Kalamees, T.; Eskola, L.; Palonen, J.; Kurnitski, J.; Valovirta, I.; Mikkilä, A.; Jokisalo, J. Puurunkoisten Pientalojen Kosteus- Ja Lämpötilaolosuhteet, Ilmanvaihto Ja Ilmatiiviys (Moisture And Temperature Conditions of Wooden Framed Detached Houses, Ventilation And Infiltration); Technical Report; Tempere University of Technology, Department of Civil Engineering, Structural Engineering Laboratory: Tampere, Finland, 2005. (In Finnish)

70. Vinha, J.; Korpi, M.; Kalamees, T.; Jokisalo, J.; Eskola, L.; Palonen, J.; Kurnitski, J.; Aho, H.; Salminen, M.; Salminen, K.; et al. Asuinrakennusten Ilmanpitäryys, Sisäilmasto Ja Energiatalous (Airtightness, Indoor Climate and Energy Economy of Detached Houses and Apartments); Technical Report; Tampere University of Technology, Department of Civil Engineering: Tampere, Finland, 2009. (In Finnish)

71. Laine, K. Rakennusmateriaalisen Rakennusfysikaaliset Ominaisuudet (Building Physical Properties of Construction Materials). Master's Thesis, Tampere University of Technology, Tampere, Finland, 2010. (In Finnish)

72. Nieminen, J. Mikä on Passiivitalo? (What Is a Passive House?); VTT Technical Research Centre of Finland: Espoo, Finland, 2006. (In Finnish)

73. Kissock, K.; Selvacanabady, A.; Raghavan, N. Simplified model for ground heat transfer from slab-on-grade buildings. ASHRAE Trans. 2013, 119, 456-468.

74. Järventausta, P.; Repo, S.; Trygg, P.; Rautiainen, A.; Mutanen, A.; Lummi, K.; Supponen, A.; Heljo, J.; Sorri, J.; Harsia, P.; et al. Kysynnän Jousto—Suomeen Soveltuvat Käytännön Ratkaisut Ja Vaikutukset Verkkoyhtiöille (Demand Response-Practical Solutions Applicable in Finland, and The Implications for Network Operators); Technical Report 2015; Tampere University of Technology: Tampere, Finland, 2015. (In Finnish)

75. Building Information Foundation RTS sr. RT 73-10616 Asunnon Sähköasennukset (Electrical Installations in Dwellings); Building Information Foundation RTS sr: Helsinki, Finland, 1996. (In Finnish) 
76. Seuna, S. Vesikiertoinen Vai Kuiva Lämmönjakojärjestelmä? (Hydronic or Dry Heat Distribution System?) Available online: https:/ / www.energiatehokaskoti.fi/suunnittelu/talotekniikan_suunnittelu/lammitys / vesikiertoinen_vai_kuiva_lammonjakojarjestelma (accessed on 2 August 2017). (In Finnish)

77. Glen Dimplex Group. QM070 QM100 QM125 QM150 Quantum Installation Instructions; Glen Dimplex Group: Dublin, Ireland, 2017.

(C) 2018 by the authors. Licensee MDPI, Basel, Switzerland. This article is an open access article distributed under the terms and conditions of the Creative Commons Attribution (CC BY) license (http://creativecommons.org/licenses/by/4.0/). 